\title{
Review Article \\ The Role of Cytidine Deaminases on Innate Immune Responses against Human Viral Infections
}

\author{
Valdimara C. Vieira ${ }^{1}$ and Marcelo A. Soares ${ }^{1,2}$ \\ ${ }^{1}$ Programa de Oncovirologia, Instituto Nacional de Câncer, Rua André Cavalcanti, No. 37-4 Andar, Bairro de Fátima, \\ 20231-050 Rio de Janeiro, RJ, Brazil \\ ${ }^{2}$ Departamento de Genética, Universidade Federal do Rio de Janeiro, 21949-570 Rio de Janeiro, RJ, Brazil
}

Correspondence should be addressed to Marcelo A. Soares; masoares@biologia.ufrj.br

Received 16 March 2013; Revised 29 May 2013; Accepted 31 May 2013

Academic Editor: Enrique Medina-Acosta

Copyright (C) 2013 V. C. Vieira and M. A. Soares. This is an open access article distributed under the Creative Commons Attribution License, which permits unrestricted use, distribution, and reproduction in any medium, provided the original work is properly cited.

The APOBEC family of proteins comprises deaminase enzymes that edit DNA and/or RNA sequences. The APOBEC3 subgroup plays an important role on the innate immune system, acting on host defense against exogenous viruses and endogenous retroelements. The role of APOBEC3 proteins in the inhibition of viral infection was firstly described for HIV-1. However, in the past few years many studies have also shown evidence of APOBEC 3 action on other viruses associated with human diseases, including HTLV, HCV, HBV, HPV, HSV-1, and EBV. APOBEC3 inhibits these viruses through a series of editing-dependent and independent mechanisms. Many viruses have evolved mechanisms to counteract APOBEC effects, and strategies that enhance APOBEC 3 activity constitute a new approach for antiviral drug development. On the other hand, novel evidence that editing by APOBEC 3 constitutes a source for viral genetic diversification and evolution has emerged. Furthermore, a possible role in cancer development has been shown for these host enzymes. Therefore, understanding the role of deaminases on the immune response against infectious agents, as well as their role in human disease, has become pivotal. This review summarizes the state-of-the-art knowledge of the impact of APOBEC enzymes on human viruses of distinct families and harboring disparate replication strategies.

\section{Introduction}

The human immune system is constantly challenged by invading pathogens, against which it acts by eliminating them or reducing their impact once infection is established. Current and emerging viruses constitute an important fraction of these pathogens that are able to develop short to life-long persistent infections, to some of which no protective vaccines are yet available. In this regard, a better understanding of the mechanisms by which innate and adaptive immunity restricts viral infections and/or modulate viral pathogenesis is urged.

The innate immune system constitutes the first line of defense against viruses, initiating an antiviral response. Viruses are recognized by this system primarily through detection of their nucleic acids, either their packaged genome or viral replication intermediates within the infected cell [1]. Tolllike receptors are good examples of the former viral sensing mechanisms, while the latter are represented by RIG-I-like or DAI and AIM2 receptors $[2,3]$. These types of recognition induce the transcription of proinflammatory cytokines and type I interferons (IFNs). These, on their hand, activate the expression of hundreds of IFN-stimulated genes (ISGs) which will engage in counteracting virus replication and spread [4].

Among the ISGs, the genes encoding the family of apolipoprotein B mRNA-editing catalytic polypeptide (APOBEC) cytidine deaminases have been largely studied in the last years. Mounting evidence suggest that these enzymes are key players in restricting infections by different viruses. In this review, we summarize the state-of-the-art knowledge of the impact of APOBEC enzymes on human viruses of distinct families and harboring disparate replication strategies.

\section{The APOBEC Family of Deaminases}

The APOBEC family of proteins comprises a group of cytidine deaminases that are able to edit DNA and/or RNA sequences. Although it belongs to a larger superfamily of 
deaminases, APOBECs are restricted to vertebrates [5]. In humans, the family comprises eleven members with distinct functions: activation-induced deaminase (AID) and APOBEC1, whose genes are located in chromosome 12; APOBEC2, whose gene is in chromosome 6; seven APOBEC3 genes, located in chromosome 22; and APOBEC4, whose gene is located in chromosome 1 [6-10]. The members of this family are distinguished by the presence of one or two catalytic domains containing a zinc-binding deaminase motif, characterized by the conserved amino acid sequences $\mathrm{H}-\mathrm{X}-\mathrm{E}-\mathrm{X}_{(23-28)}-\mathrm{P}-\mathrm{C}-\mathrm{X}_{(2-4)}-\mathrm{C}(\mathrm{X}$ is any amino acid; Figure 1$)$ [9]. The deamination mediated by these enzymes involves the hydrolytic removal of the amino group at the $\mathrm{C} 4$ position of a cytidine $(\mathrm{C})$ or deoxycytidine $(\mathrm{dC})$, generating a uridine $(\mathrm{U})$ or deoxyuridine (dU) (Figure 1) [11].

APOBEC1 (A1), the first member of the family to be described, is an RNA-editing enzyme [12] but also presents the ability to edit DNA in bacterial assays [13]. It is primarily expressed in the gastrointestinal compartment and catalyzes the posttranscriptional editing of the apolipoprotein $\mathrm{B}(a p o B)$ mRNA. A1 is a nucleocytoplasmic protein [14], and the $a p o B$ mRNA editing occurs in the nucleus in the presence of the APOBEC-1 complementation factor (ACF) $[15,16]$. A1 edits this mRNA at a single base, resulting in the formation of a premature stop codon and leading to the synthesis of a truncated protein (ApoB48) [12]. As a consequence, the human gut produces two forms of ApoB, a longer (ApoB100) and a shorter (ApoB48), involved in the transport of endogenously produced cholesterol and triglycerides and the absorption and transport of exogenous dietary lipids, respectively [17]. Recently, additional mRNA targets of APOBEC1 have been described; the interaction occurs at AU-rich segments of their $3^{\prime}$ untranslated regions. A1 may thus play a role regulating the stability of such specific mRNAs [18, 19].

AID, which deaminates single stranded DNA [20, 21], is predominantly cytoplasmic and shuttles between the nucleus and the cytoplasm [22-25]. It is expressed in germinal center $B$ cells and is essential for the events of class switch recombination and somatic hypermutation during the process of antibody diversification [26-28]. AID has also been reported as involved in DNA demethylation [29-31].

APOBEC2 is expressed in heart and skeletal muscles [8], and although its precise physiologic role is not established, its expression appears to be essential to muscle development [32].

The APOBEC3 group comprises seven proteins in humans: APOBEC3A, APOBEC3B, APOBEC3C, APOBEC3DE, APOBEC3F, APOBEC 3G, and APOBEC $3 \mathrm{H}$. A3A, A3C, and $\mathrm{A} 3 \mathrm{H}$ present one copy of the zinc-binding domain, while the remaining harbor two copies; the $\mathrm{N}$ - and $\mathrm{C}$-terminal domains are named CD1 and CD2, respectively (Figure 1). In those three enzymes, only CD2 is catalytically active $[13,33$, 34]. A3 enzymes are capable of editing single-stranded DNA and recognize specific target sequences. A3G and $\mathrm{A} 3 \mathrm{~F}$, for example, edit C's preferentially at $\mathrm{C} \underline{\mathrm{C}}$ and $\mathrm{T} \underline{\mathrm{C}}$ dinucleotide contexts (GG and AG in the complementary DNA strand), respectively [35-38].

A3 enzymes play an important role on the innate immune system, acting on host defense against exogenous viruses and endogenous retroelements [39-42]. Viral restriction occurs mainly by their DNA editing mechanism, but A3s also display editing-independent phenotypes [38, 43-45], as will be discussed later. They are further possibly implicated into a specific pathway of exogenous DNA clearance in human cells [46]. More recently, lines of mounting evidence have also shown that A3 enzymes insert mutations in human nuclear and mitochondrial DNA, suggesting roles in DNA catabolism [47]. On the other hand, this phenomenon may represent a possible source of mutations towards the development of cancer $[47,48]$.

A3 enzymes localize to the cell cytoplasm and/or nucleus, enabling the protection of both compartments through restriction of nuclear (such as the human papillomavirus, the herpes simplex virus, and non-LTR retrotransposons) or cytoplasmic (like the hepatitis B virus, retroviruses, and LTR retrotransposons) replicating elements. A3D, A3F, and A3G are known to be cytoplasmic [40, 49]; A3B localizes to the nucleus [50], while $\mathrm{A} 3 \mathrm{~A}, \mathrm{~A} 3 \mathrm{C}$, and $\mathrm{A} 3 \mathrm{H}$ are found both in the nucleus and in the cytoplasm [40,51]. Noteworthy, different $\mathrm{A} 3 \mathrm{H}$ haplotypes present distinct localizations; the protein encoded by haplotype I is mainly nuclear, while the one encoded by haplotype II is predominantly cytoplasmic [51]. With respect to $\mathrm{A} 3 \mathrm{~A}$, it has been recently reported that its endogenous version in primary $\mathrm{CD} 14^{+}$monocytes and in the monocytic cell line THP-1 localizes to the cytoplasm, contrasting with the broad nucleocytoplasmic distribution observed upon $\mathrm{A} 3 \mathrm{~A}$ transfection, an observation likely explained by artificial overexpression of the enzyme [52].

In addition to presenting distinct subcellular localization, some APOBEC 3 proteins also display an intracellular mode of regulation by localization into specific subcellular structures. It is known that $A 3 G$ is present in two distinct molecular forms within the cell: a form of low molecular mass (LMM) and another in ribonucleoproteic complexes of high molecular mass (HMM) [53-55]. The HMM complex is enzymatically inactive and can be converted into LMM complexes, enzymatically active, through RNase digestion [53]. Besides A3G, other APOBECs like A3C, A3F, and A3H also show the ability of assembling into HMM complexes [56-58].

It has been shown that the switch between HMM and LMM can be stimulated by different cytokines $[59,60]$, and the predominant form varies among different cell types or distinct cell type subsets. The presence of LMM A3G has been related to a reduced susceptibility to HIV-1 infection, as is suggested as postentry restriction factor for this virus [53, $60,61]$. For example, unstimulated peripheral blood $\mathrm{CD}^{+}$ T-cell lymphocytes and monocytes, which are nonpermissive to HIV-1 infection, present LMM A3G. However, when CD4 ${ }^{+}$ T-cell lymphocytes are activated or the monocytes stimulated to differentiate into macrophages, they shift their $A 3 G$ profile to HMM [53]. Noteworthy, the knockdown of $A 3 G$ in unstimulated $\mathrm{CD}^{+} \mathrm{T}$ cells does not turn them permissive to infection, suggesting that the presence of LMM A3G in the cells is not the unique determinant for their resistance to HIV-1 $[62,63]$. Moreover, LMM A3G is preferentially packaged into HIV-1 particles [56, 64-66]. Finally, HMM 


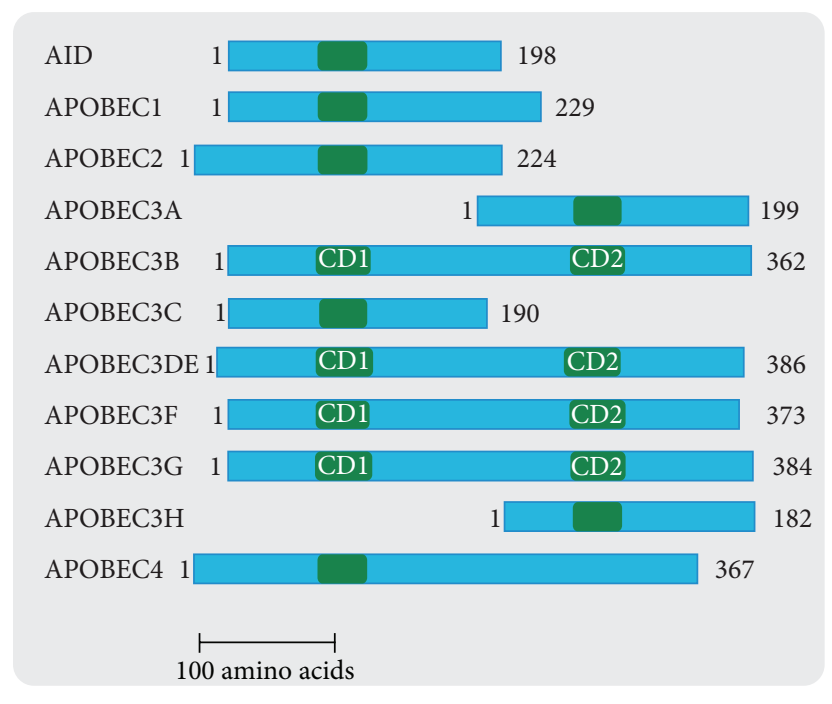

(a)
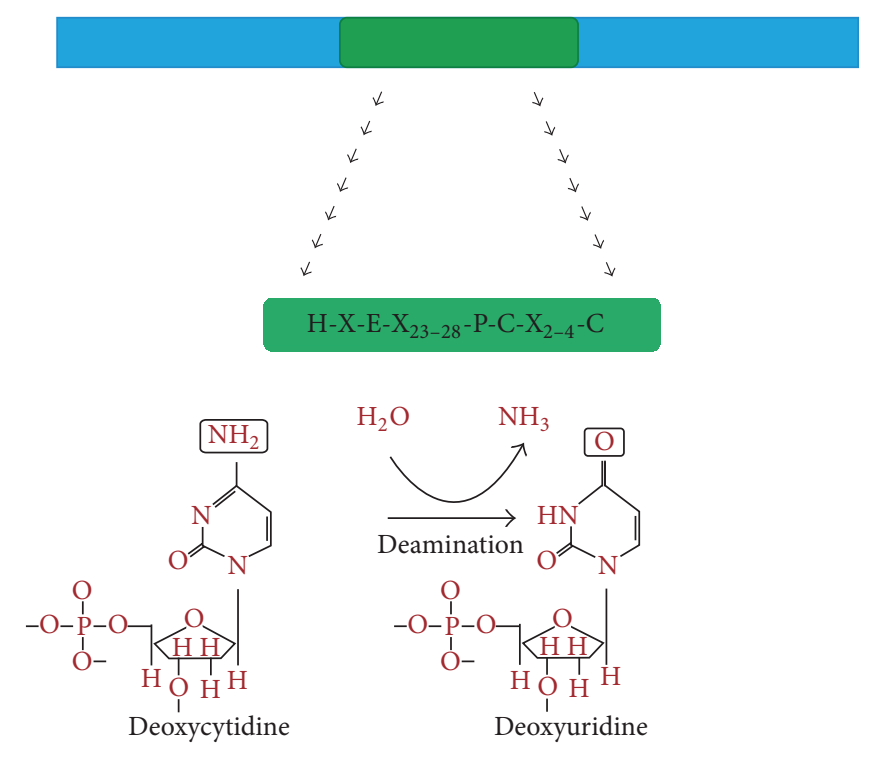

(b)

FIGURE 1: Structure and function of human APOBEC proteins. (a) Schematic representation of APOBEC proteins. The zinc-binding motifs, represented by the catalytic domains (CD) and present in single or double copies, are depicted in green. In the proteins that harbor two CD copies, the $\mathrm{N}$ - and C-terminal domains are named CD1 and CD2, respectively. APOBEC proteins are drawn to scale, and the total number of amino acids is shown to the right of each version. The scale bar represents the length of 100 amino acids. (b) The conserved amino acid sequence of the zinc-binding motif is shown; the hydrolytic deamination reaction mediated by these enzymes is shown at the bottom of the figure.

A3G is also able to interact with and sequester Alu RNA elements, inhibiting their transposition and evidencing the role of different $\mathrm{A} 3 \mathrm{G}$ molecular forms in the restriction of retroelements [67].

A3G and $\mathrm{A} 3 \mathrm{~F}$ are also able to accumulate in processing bodies (P-bodies) and stress granules, where they interact with RNAs and several proteins that regulate their metabolism [68-71]. However, the functional consequences of the occurrence of $\mathrm{A} 3$ proteins in those structures are not yet clear [72].

APOBEC4 is expressed in testicles, and its function is still unknown [10]. Like A2, A4 does not present mutagenic activity in bacterial or yeast assays [73].

APOBEC proteins are found throughout vertebrates, with AID and APOBEC2 being ancestral members of the family and APOBEC1 and APOBEC3 being more recent, while the origins of APOBEC4 are not clear [74-77]. The APOBEC3 enzymes are exclusively found in mammals $[5,78]$, and their gene copy number is species-specific. While mice have only a single $A P O B E C 3$ gene, pigs have two, sheep and cattle have three, cats have four, horses have six, and primates have at least seven $A P O B E C 3$ genes $[5,9,79,80]$.

The evolutionary history of the $A P O B E C 3$ genes involves expansion, divergence, selection and extinction of specific A3 copies [80]. It is believed that the genome of the mammalian ancestor encoded for at least one ancestral $A P O B E C 3$ gene and that this gene family expanded in the different lineages as a response to changes in viral, retroviral, and retrotransposon pressure $[78,79]$. Interestingly, the rapid expansion of the $A P O B E C 3$ locus in primates is correlated with a marked reduction in retrotransposon activity, suggesting an important role in the host genome defense against retroelements $[81,82]$.

There is evidence that APOBEC3 proteins are able to restrict non-LTR and LTR retrotransposons, including both long interspersed nuclear elements (LINEs) and short interspersed nuclear elements (SINEs) [40, 57, 83-87]. While for some murine LTR retrotransposons, like IAP e MusD, DNA deamination was observed as part of the restriction mechanism $[39,85]$, the exact mechanism and the retrotransposition step targeted by APOBEC3 is unknown for non-LTR elements (reviewed in [82]).

It is interesting to note that AID and APOBEC1 from multiple species have been shown to possess activity against retroelements [86, 88-90] and exogenous viruses [89, 91-93], suggesting that these proteins may also have a role in innate immunity of some vertebrates $[82,89,92]$.

\section{Role of APOBEC Enzymes on Different Human Viral Infections}

3.1. Human Immunodeficiency Virus (HIV). The human immunodeficiency virus (HIV) is a member of the Retroviridae family, and belongs to the Lentivirus genus, which characterizes viruses of slow symptomatology. As a retrovirus, HIV harbors a genome consisting of two single-stranded RNA molecules of positive polarity that undergoes a reverse transcription step (through a complementary DNA-cDNAmolecule) carried out by its encoded reverse transcriptase (reviewed in [111]). The cDNA is then integrated into the host 
cell genome, from where the viral genes are transcribed by the host RNA polymerase II. In addition to the essential genes, HIV also encodes several accessory and regulatory proteins that enhance virus replication and burden, being the viral infectivity factor (Vif) among them (reviewed in [111]).

The hypermutation mediated by APOBEC enzymes in HIV type 1 (HIV-1) is well described (Figure 2). It is known that in HIV-1-infected cells, in the absence of a functional Vif, A3G molecules are incorporated into incoming virus particles. This packaging is mediated by the interaction of A3G with the nucleocapsid (NC) domain of the Gag protein [112-116] and occurs in an RNA-dependent manner [114, $115,117-120]$. After a new infection, the editing process occurs during viral reverse transcription. A3G deaminates $\mathrm{dC}$ residues in the negative strand of the complementary DNA (cDNA), originating dU. These nucleotides serve as templates for the incorporation of $\mathrm{dA}$ in the positive strand and are evidenced as G-to-A changes in the proviral DNA. The frequency of edited dC's in the viral genome can exceed $10 \%$ of the sites $[38,121]$. The excessive number of changes results in loss of genetic information and production of largely defective virions in the subsequent replication cycle.

A reduction of viral reverse transcription products is also observed in the presence of A3G. It has been hypothesized that the presence of dU's in the retroviral DNA could be recognized as anomalous, leading to its degradation even before its integration into the host cell genome (Figure 2). This would occur by removal of the uracil residues by uracil-DNA glycosylases (UDGs), followed by apurinic/apyrimidinic (AP) endonuclease-mediated degradation [122, 123]. Noteworthy, it has been shown that APOBEC-mediated restriction occurs even in the absence of UDGs such as UNG2 and SMUG1 [124, 125], leaving the requirement of retroviral DNA degradation for virus restriction as an open question.

In addition to restricting viral infection through hypermutation, A3G also exert editing-independent mechanisms of restriction. These involve the interference with reverse transcription and with proviral integration by disturbing tRNA primer annealing and removal, DNA synthesis initiation and elongation and strand transfer reaction [43-45, 126135].

Further to the direct mechanisms of viral inhibition, A3G appears to play a pivotal role in the activation of the host immune system. It has been shown that the generated pool of defective viruses encoding truncated or misfolded proteins represents an important source of viral antigens, associated with a strong activation of HIV-1-specific CD8+ cytotoxic T-cells [136]. APOBEC3 may also enhance the recognition of HIV-infected cells by natural killer cells through the activation of the DNA-damage repair response by viruses harboring uridines in their genomes [137].

HIV-1, like the majority of lentiviruses, counteracts the restriction mediated by the A3 enzymes through expression of the Vif protein $[138,139]$. The main mechanism of action assigned to Vif is the induction of $\mathrm{A} 3 \mathrm{G}$ protein degradation via proteasome. Vif simultaneously binds to $A 3$ and to an E3 ubiquitin-ligase complex, leading to polyubiquitination of $\mathrm{A} 3 \mathrm{G}$ and its consequent degradation [138-141]. Vif is also able to prevent $\mathrm{A} 3 \mathrm{G}$ packaging into the virion in a degradation-independent manner and to interfere with A3G mRNA translation, thus reducing the intracellular levels of the protein (Figure 2) [142-147].

APOBEC3F (A3F) has also been associated with HIV restriction in a consistent manner. However, A3G seems to have a more important role in viral restriction of cells targeted by HIV, whereas the role of $\mathrm{A} 3 \mathrm{~F}$ seems to be dispensable for virus restriction in these cells $[148,149]$. A3A, A3B, A3C, $\mathrm{A} 3 \mathrm{DE}$, and some $\mathrm{A} 3 \mathrm{H}$ haplotypes have also been implicated in restriction [148, 150-157], although controversial results have been observed (reviewed in [158]).

HIV hypermutated proviral DNA sequences have been reported in several in vivo studies. Yet some reports have shown a correlation between hypermutation and a favorable clinical outcome, this relationship is not consensual. In a population level analysis of HIV-1 subtype B near fulllength proviral sequences, hypermutation levels were associated with reduced pretreatment viremia [101]. In agreement with this, higher hypermutation levels were observed in patients with low HIV viral loads $(<10,000$ copies/mL for at least 3 years) in another study [159]. The presence of hypermutation was also correlated with higher $\mathrm{CD} 4^{+} \mathrm{T}$ cell counts [160]. More recently, Kourteva et al. [161] found more A3G-hypermutated sites in proviral sequences derived from HIV long-term nonprogressors (LNTP) compared to noncontrollers (NC). On the other hand, some studies could not find such associations, either in adults or in children [162164].

A more consistent association has been observed between the APOBEC3 mRNA levels and clinical outcomes. Several studies showed a positive correlation of A3 levels with $\mathrm{CD} 4^{+}$ T-cell counts and a negative correlation with HIV-1 viral load $[159,161,165,166]$ or viral set point [167]. However, two studies could not find an association between A3G levels and $\mathrm{CD}^{+}{ }^{+} \mathrm{T}$-cell counts or viral load $[104,168]$. APOBEC3G expression has also been inversely correlated with provirus burden [161] and positively correlated with the level of G-to-A changes $[159,161,162]$. A3G has also been found significantly increased in HIV-exposed uninfected (EU) compared to healthy controls $[159,169]$ or infected individuals [169]. The level of expression in EU significantly decreased after one year from HIV diagnosis and subsequent treatment of their partners. This suggests that, in these individuals, exposure to HIV can trigger APOBEC3G expression in the absence of infection and that the expression decreases with cessation of exposure [159]. Interestingly, the higher expression of APOBEC3G in EU was seen not only in PBMCs but also in cervical tissues, and may be important for the susceptibility to sexually transmitted HIV infection [169].

Higher levels of APOBEC3G mRNA were observed in LTNPs when compared to HIV-uninfected subjects and progressors [165]. Accordingly, higher levels of A3G and A3F were found in LTNP when compared to noncontrollers [161], and higher levels of $\mathrm{A} 3 \mathrm{G}$ and $\mathrm{A} 3 \mathrm{~B}$ were also found in slow progressing patients (SP) when compared to AIDS patients [166]. However, in a group of perinatally HIV-infected children, no correlation was observed between A3G/A3F expression and disease progression [164]. Paradoxically, A3G levels were higher in HIV-negative when compared with HIV 


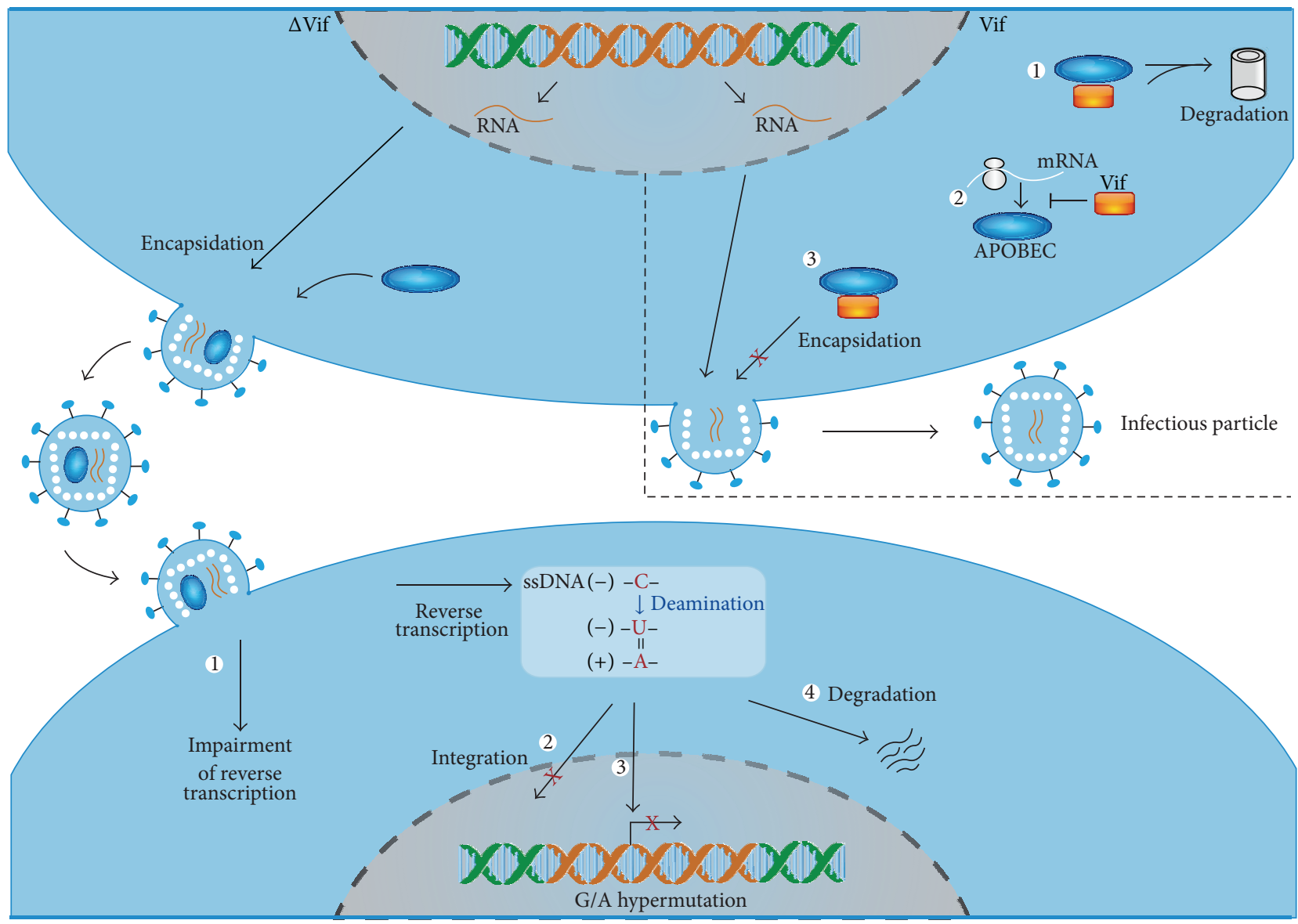

FIGURE 2: Mechanism of action of APOBEC3 (A3) and Vif in the HIV-1 life cycle. At the top panel, a virus-producing cell in the absence (left) or in the presence (right) of a functional Vif protein is shown. In the presence of Vif (orange rectangle), A3 (blue ellipse) is primarily targeted to proteasomal degradation (1); Vif can also block A3 mRNA translation (2) and prevent A3 packaging into the virion in a degradationindependent manner (3). In the absence of Vif, A3 molecules are packaged into incoming virus particles. After a new infection (bottom panel), A3 exerts its antiviral activity in multiple ways. A3 can interfere with reverse transcription in a deamination-independent manner (1). A3 can also interfere with proviral integration through the formation of abnormal viral DNA ends (2). In the hypermutation process, A3 mainly deaminates $\mathrm{dC}$ residues in the negative strand of the complementary viral DNA, originating dU, that serves as template for the incorporation of $\mathrm{dA}$ in the positive strand. If able to integrate, hypermutated proviruses are normally largely defective (3). Alternatively, viral DNA containing multiple dU can also be degraded before integration (4).

positive individuals $[104,166,168]$, including matched preand postinfection samples from the same subjects. This may suggest that APOBEC3G transcription is rapidly downregulated upon HIV-1 infection [104]. In view of these confounding evidence, additional work is necessary to robustly define the role of A3 expression in the control of HIV infection and disease progression.

Due to the potential antiviral role of the A3 enzymes, therapeutic interventions have been idealized to enhance their action and lead to viral inhibition through hypermutation [170-174]. In this sense, molecules have been identified that are able to interact with A3G and counteract Vif-mediated degradation [171] or to induce Vif degradation in the presence of A3G [172]. On the other hand, it is possible that the editing mediated by the APOBEC enzymes, upon sublethal conditions (which do not drive virus extinction), acts in the diversification of the viral genome, providing source for the selection and evolution of highly fit variants. This can favor, for example, the acquisition of immune system escape mutations or drug resistance mutations [75, 175-182]. In this regard, novel therapeutic strategies based on complete A3G inhibition, eliminating this additional source of virus diversification, have also been proposed $[174,183,184]$.

\subsection{Human T-Cell Lymphotropic Virus (HTLV). HTLV is a} complex retrovirus belonging to the Deltaretrovirus genus. In most cases infection by HTLV-1 is asymptomatic; however, up to $5 \%$ of the infected subjects develop adult T-cell leukemia (ATL) and another 1-2\% develop HTLV-1-associated myelopathy/tropical spastic paraparesis (HAM/TSP) $[185,186]$.

Like HIV-1, HTLV targets mainly CD $4^{+}$T lymphocytes [187], and therefore, it would be exposed to several A3 enzymes that are expressed in this cell type [188]. HTLV does not encode any product with Vif-like, A3 antagonist 
function, and it is apparently incapable of inducing A3 degradation in cell culture $[34,189]$. Unexpectedly, however, hyperedited HTLV sequences appear to be rare. Yet HTLV hypermutated sequences with estimated frequencies between 0.1 and $5 \%$ have been observed in vitro, no instance of hypermutation was reported in PBMC from HTLV-infected patients [34]. Moreover, a retrospective analysis of previously published HTLV sequences has identified a single hypermutated sequence recovered from an HTLV-1 infection of an animal model [190].

Although rare in vivo, HTLV hypermutated sequences were recovered from cell lines derived from ATL and HAM/TSP patients. The main context of the observed changes was GG, followed by GA and GC, suggesting the involvement of $\mathrm{A} 3 \mathrm{G}$ and also of other $\mathrm{A} 3$ such as $\mathrm{A} 3 \mathrm{~A}$ and A3B in HTLV hypermutation [189]. Despite the fact that A3G is able to edit the viral genome [191, 192], some studies have shown that HTLV-1 is resistant or poorly susceptible to this enzyme $[34,189,192,193]$, in agreement with the low frequency of editing observed in vivo.

Two possible reasons for the low frequency of hypermutated HTLV sequences in vivo, when compared to HIV hypermutation, have been discussed. One of the possibilities resides in the differences of replicative strategies of these two viruses. After primary infection, HTLV presents a low level of productive replication, and the proviral genome is mainly replicated through oligoclonal expansion of infected cells, a fact that contrasts with the high rate of de novo cell infection seen during chronic HIV disease [185, 194-196]. Therefore, it has been suggested that the infrequent replication via reverse transcription seen in HTLV infection represents a reduction of opportunities for APOBEC3-mediated edition to occur. Moreover, a direct resistance mechanism to A3G has been described in HTLV-1. Through a cis-acting exclusion mechanism, elements in the C-terminal region of the HTLV-1 nucleocapsid inhibit $\mathrm{A} 3 \mathrm{G}$ packaging to the particle, resulting in reduced efficiency of its packaging in HTLV-1 particles when compared to HIV $\Delta$ vif virus-like particles [197].

Recently, an analysis of proviral genomes of 60 ATL patients and asymptomatic carriers showed that G-to-A changes are the most frequent nucleotide substitutions. These changes occurred preferentially in the target context of A3G and were involved in the generation of multiple missense substitutions. It was then suggested that HTLV-1-infected cells can take advantage of A3G activity to escape the host immune system by abrogating the expression of viral proteins [191].

3.3. Hepatitis B Virus (HBV). HBV belongs to the Hepadnaviridae family and presents a circular, partially double stranded DNA genome [198]. It replicates through reverse transcription of an intermediate pregenomic RNA. It is estimated that two billion people have been infected and more than 240 million have chronic liver infections worldwide [199]. HBV infection can cause acute and chronic liver disease, including cirrhosis and hepatocellular carcinoma [198].
A number of studies have shown that the HBV genome is susceptible to human APOBEC enzymes. In addition to A1 and AID, all A3 enzymes except for A3DE were able to edit the viral genome in vitro [200-206] with editing levels estimated between $10^{-2}$ and $10^{-5}$ [205]. Viral genome editing occurs preferentially in the negative DNA strand resulting in G-to-A changes in the positive strand; C-to-T changes have also been observed in the positive strand, evidencing editing of both viral DNA strands [202].

In addition to the identification of $\mathrm{HBV}$ sequences extensively edited by APOBEC enzymes, several studies have shown evidence of restriction to virus replication in vitro, by both editing-dependent and -independent mechanisms [201, 207, 208]. In this sense, a strong inhibitory effect of A3G has been described [201, 204, 207, 208], and a reduction of approximately 30 -fold in the levels of viral DNA in the presence of A3G expression has been shown [204]. Turelli et al. [207] showed that A3G leads to a reduction of viral DNA and also of core-associated RNA; this effect was sustained when a catalytically-inactive A3G mutant was used. Among the possible deamination-independent mechanisms of action are the inhibition of pregenomic RNA packaging and the interference of reverse transcription [201, 207, 208]. Additional unrelated factors may account for the suppression of $\mathrm{HBV}$ replication in hepatocytes, including the inhibition of $\mathrm{HBV}$ transcription through the interaction of $\mathrm{A} 3 \mathrm{~B}$ with the heterogeneous nuclear ribonucleoprotein K (hnRNP-K), a positive regulator of HBV expression [209].

In the healthy human liver, low to moderate APOBEC expression levels are observed $[9,188,210]$. However, some of these enzymes, particularly A3G, have their expression significantly increased in primary hepatocytes and in hepatoma cell lines in response to stimulation by interferon alpha and gamma [210-212]. In agreement with those data, low hypermutation levels (from $10^{-4}$ to $0.6 \%$, depending on the method used) have been described in patients with acute and chronic HBV infection [202, 213, 214]. This has led to the hypothesis that hypermutation is intrinsic to the natural response to $\mathrm{HBV}$ infection and that it may contribute to the noncytolytic clearance of HBV [202, 207, 210]. However, there are no current in vitro evidence supporting a major role of A3 on the IFN-mediated HBV inactivation in the liver $[215,216]$.

In contrast to the moderate levels of APOBEC expression in the healthy liver, overexpression of these enzymes is observed in cirrhotic tissues, likely resultant from the high production of cytokines associated with the chronic inflammatory response against the infection. Consequent to this increase in APOBEC expression, high levels of HBV hypermutation have been observed, reaching $35 \%$ of the sequences in some cases [206].

A potential role of APOBEC3 has been suggested on the oncogenesis of the hepatocellular carcinoma (HCC). It has been shown that some APOBEC3 enzymes are able to generate truncation mutants of the $\mathrm{HBx}$ viral protein, leading to a selective advantage to preneoplastic and neoplastic hepatocytes [217]. Moreover, A3B was found to be overexpressed in HCC tissues. In HepG2 cells, A3B overexpression promoted their growth and led to an upregulation of the heat 
shock transcription factor-1 (HSF-1), which was also found to be upregulated in HCC [217]. HSF-1 is a regulator of the heat-shock response and is known to facilitate malignant transformation, cancer cell survival, and proliferation in model systems. Recently, it has been shown to coordinate a transcriptional program in malignancy, which differs from that induced by thermal stress. This program activates cancerspecific genes that support oncogenic events and was found to be active in breast, colon, and lung tumors [180].

3.4. Hepatitis C Virus (HCV). HCV belongs to the Flaviviridae family and presents a positive sense, single-stranded RNA genome [218]. HCV is a causative agent of acute and chronic liver diseases. Chronic HCV infection, along with chronic HBV infection and its associated liver cirrhosis, constitutes major risk factors for HCC development [219]. It has been recently shown that $\mathrm{A} 3 \mathrm{G}$ is able to inhibit $\mathrm{HCV}$ replication in vitro. However, viral hypermutated sequences have not been found, suggesting a role of deaminase-independent mechanisms of viral inhibition. Considering that A3G targets ssDNA, such lack of hypermutation is expected for $\mathrm{HCV}$, which presents exclusively RNA as genomic material during all phases of its replication. Interestingly, it has also been shown that the presence of exogenous HIV-1 Vif led to an intracellular decrease of A3G and consequently to an increase of $\mathrm{HCV}$ replication, suggesting the involvement of Vif in the HIV-1/HCV coinfection [220].

As previously mentioned, the APOBEC enzymes are expressed at moderate levels in the normal liver. However, $\mathrm{HCV}$ infection is also associated to an increase in expression of those enzymes. In patients chronically infected by $\mathrm{HCV}$, a significant increase in A3G expression was seen in hepatocytes and in lymphocytes [221]. Overexpression of APOBEC has also been observed in HCV/HBV coinfection [206].

APOBEC3 also appears to play an important role on treatment with exogenous interferon alpha (IFN $\alpha)$ in vivo. Jiménez-Sousa et al. [222] analyzed the profile of gene expression in $\mathrm{HCV}$ chronically infected patients after 12 weeks of treatment with IFN $\alpha /$ ribavirin (RBV), and $\mathrm{A} 3 \mathrm{~A}$ was among the IFN-induced genes that was upregulated in early responders but not in nonresponders. In another study, a significant increase in the expression of $\mathrm{A} 3 \mathrm{G} / 3 \mathrm{~F}$ was observed in CD4 T-cell lymphocytes of HIV/HCV coinfected patients during treatment with pegIFN/RBV. In that study, APOBEC3 induction was correlated with the levels of HIV hypermutation [223].

In addition to the $\mathrm{HCV}$ restriction phenotype during the natural course of infection and during treatment, APOBEC3 enzymes have also been suggested as a putative target in antiHCV drug development. Treatment of HCV-infected Huh7.5 cells with two stabilizing components of APOBEC3G, which increased its intracellular levels, inhibited HCV replication [220].

3.5. Human Papillomavirus (HPV). HPV belongs to the Papillomaviridae family and presents a circular, double-stranded DNA genome. Infection by HPV is a necessary condition for the development of cervical cancer, but the evolution to invasive carcinoma only occurs in a fraction of the infected women [224].

Vartanian et al. [225] showed that both strands of HPV DNA are susceptible to APOBEC editing. In that study, nine HPV16-positive precancerous cervical and six HPV1apositive plantar wart samples were analyzed for the presence of hypermutation. Of the samples, two HPV-16 and one HPVla presented edited sequences. In vitro $\mathrm{A} 3 \mathrm{~A}, \mathrm{~A} 3 \mathrm{C}$ and $\mathrm{A} 3 \mathrm{H}$ were shown to be able to hyperedit HPV DNA. The preferred in vitro dinucleotide context for these three A3 enzymes correlated with the editing contexts observed in vivo, suggesting that $\mathrm{APOBEC} 3 \mathrm{~A}, \mathrm{APOBEC} 3 \mathrm{C}$, and $\mathrm{APOBEC} 3 \mathrm{H}$ may be involved in edition of HPV in vivo.

3.6. Human Herpesviruses (HHV). Human APOBEC enzymes have also been shown to restrict DNA genome viruses belonging to the Herpesviridae family [226, 227]. Herpesviruses are enveloped viruses harboring a doublestranded DNA genome. They are associated with a range of different diseases and are able to establish latent infection and persist in the infected host for life [228-231].

Herpes simplex virus type 1 (HSV-1) can cause from mild infections of mucous membranes, including herpes labialis and genital infections, to life threatening infections, such as HSV encephalitis [228, 229]. Suspène et al. [226] have identified the presence of HSV hypermutated genomes in four out of eight oral lesions. Overexpression of A3C in vitro led to a fourfold reduction in viral titers and to a 10 -fold reduction in viral infectivity. Moreover, it has been shown that not only $\mathrm{A} 3 \mathrm{C}$ but also $\mathrm{AID}, \mathrm{A} 3 \mathrm{~A}$, and $\mathrm{A} 3 \mathrm{G}$ are able to edit the HSV-1 genome in vitro, although the last three had no significant impact on virus replication.

In addition to APOBEC3, APOBEC1 has also been shown to restrict HSV-1 replication in vitro in a significant fashion, in both deamination-dependent and -independent ways. Upregulation of $\mathrm{A} 1$ has been observed in rat brain tissues upon HSV-1 infection, suggesting that A1 induction during encephalitis can promote restriction to HSV-1 infection [227].

Epstein-Barr virus (EBV) can cause mucocutaneous manifestations in infectious mononucleosis and is also associated with other benign and malignant conditions, including plasmablastic lymphoma, oral hairy leukoplakia, posttransplant lymphoproliferative disorders, Burkitt's lymphoma, and Hodgkin's lymphoma [231]. In order to know whether EBV genomes were also susceptible to A3 editing, Suspène et al. [226] analyzed EBV from transformed peripheral blood mononuclear cell lines, which carry EBV in a latent form. Edited EBV DNA was found in four out of five EBV cell lines studied. A3C was found to be the most abundantly expressed $\mathrm{A} 3$ in these cell lines.

\section{Polymorphisms in APOBEC3 Genes and Susceptibility to Viral Infections}

Polymorphisms in the genes encoding APOBEC proteins have been associated with the modulation in the course of some human viral infections. A deletion of approximately $29.5 \mathrm{~kb}$ located between exon 5 of $A P O B E C 3 A$ and exon 
TABLE 1: Studies that investigated the association of $A P O B E C$ gene variants and the course of human viral infections.

\begin{tabular}{lll}
\hline $\begin{array}{l}\text { A3 family } \\
\text { member }\end{array}$ & Series description & Main findings \\
\hline A3B & $\begin{array}{l}\text { 4,216 individuals from five HIV-1 natural history } \\
\text { cohorts based in the United States of America }\end{array}$ & $\begin{array}{l}\text { Homozygous deletion associated with increased risk for } \\
\text { HIV-1 infection }(P=0.24), \text { progression to AIDS } \\
(P=0.03), \text { and viral set point }(P=0.04)\end{array}$ \\
\hline [3B & 724 HBV carriers and 469 healthy control subjects & $\begin{array}{l}\text { APOBEC3B deletion homozygosity was associated with } \\
\text { mild liver fibrosis }(P=0.0019) \\
\text { No significant association between deletion and chronic } \\
\text { HBV infection }\end{array}$ \\
\hline
\end{tabular}

361 Japanese subjects: 95 HIV-1-infected patients (48 nonprogressors and 47 slow progressors) and 266

A3B controls

453 Indian subjects: 251 HIV-1-infected patients and 202 controls

No evidence of association between the $A P O B E C 3 B$ deletion and susceptibility to HIV infection and AIDS

Higher frequency of the $A P O B E C 3 B$ deletion allele in persistent HBV carriers $(P=0.0015)$ and HCC patients 1,124 individuals with HCC, 510 individuals with A3B persistent $\mathrm{HBV}$ infection, and 826 healthy controls. All subjects were of Han Chinese ethnicity $\left(P=1.28 \times 10^{-11}\right)$ compared to controls Presence of at least one deletion allele was associated with an increased risk for persistent $\mathrm{HBV}$ infection $(P=0.0272)$ and HCC development $\left(P=1.28 \times 10^{-11}\right)$

No significant difference in the frequency of deleted $A P O B E C 3 B$ alleles between patients with chronic hepatitis $B$ and control subjects Subjects carrying the Del/Del genotype displayed a trend for increased susceptibility to HBV infection compared to the wild type genotype $(P=0.07)$ lower viral loads than patients with the wild type genotype $(P=0.0023)$

\begin{tabular}{|c|c|c|c|}
\hline $\mathrm{A} 3 \mathrm{G}$ & $\begin{array}{l}\text { 3,073 participants enrolled in six HIV/AIDS } \\
\text { prospective cohorts: } 1,481 \text { European Americans, } 949 \\
\text { African Americans from five US-based cohorts, and } \\
643 \text { patients enrolled in the Swiss HIV cohort }\end{array}$ & $\begin{array}{l}\text { For African Americans, the variant allele } 186 \mathrm{R} \text { was } \\
\text { strongly associated with a decline of } \mathrm{CD} 4^{+} \mathrm{T} \text { cells } \\
(P=0.009)\end{array}$ & [99] \\
\hline $\mathrm{A} 3 \mathrm{G}$ & $\begin{array}{l}773 \text { white French individuals: } 327 \mathrm{HIV}-1^{+} \text {( } 245 \text { slow } \\
\text { progressors; } 82 \text { rapid progressors) and } 446 \text { healthy } \\
\text { control subjects of similar ethnic origin }\end{array}$ & $\begin{array}{l}29 \text { polymorphisms with allele frequencies }>1 \% \text { were } \\
\text { identified } \\
\text { No significant associations were found between the } \\
\text { polymorphisms or haplotypes and disease progression }\end{array}$ & [100] \\
\hline $\mathrm{A} 3 \mathrm{G}$ & $\begin{array}{l}136 \text { adult HIV-infected patients from the Western } \\
\text { Australian HIV cohort }\end{array}$ & $\begin{array}{l}22 \text { single nucleotide polymorphisms were identified } \\
\text { No significant association of these APOBEC } 3 G \text { genetic } \\
\text { variants and the presence of HIV-1 hypermutation was } \\
\text { found (although an intronic allele } 6892 \mathrm{C} \text { was } \\
\text { marginally associated with HIV-1 hypermutation) }\end{array}$ & [101] \\
\hline $\mathrm{A} 3 \mathrm{G}$ & $\begin{array}{l}122 \text { Caucasian individuals exposed to HIV enrolled in } \\
\text { prospective cohort studies in Montreal }\end{array}$ & $\begin{array}{l}\text { The C40693T variant was significantly associated with } \\
\text { an increased risk of infection }(P=0.03)\end{array}$ & [102] \\
\hline A3G & $\begin{array}{l}560 \text { North Indians: } 50 \mathrm{HIV}-1 \text { exposed seronegative } \\
\text { individuals, } 190 \mathrm{HIV}-1^{+} \text {patients, and } 320 \text { healthy } \\
\text { controls }\end{array}$ & $\begin{array}{l}\text { No H186R polymorphism of } A P O B E C 3 G \text { was found } \\
\text { among North Indians }\end{array}$ & [103] \\
\hline A3G & $\begin{array}{l}250 \text { South African women at high risk for HIV-1 } \\
\text { subtype C infection }\end{array}$ & $\begin{array}{l}\text { The H186R mutation and a } 3^{\prime} \text { extragenic mutation } \\
\text { (rs35228531) were associated with high HIV viral loads } \\
(P=0.0097 \text { and } P<0.0001) \text { and decreased } \mathrm{CD} 4^{+} \\
\text {T-cell counts }(P=0.0081 \text { and } P<0.0001)\end{array}$ & [104] \\
\hline $\mathrm{A} 3 \mathrm{G}$ & $\begin{array}{l}534 \text { children perinatally exposed to HIV-1 (109 exposed } \\
\text { uninfected and } 425 \text { HIV-1-infected), from a pediatric } \\
\text { cohort of white-Hispanic ethnicity from Argentina }\end{array}$ & $\begin{array}{l}\text { HIV-1 perinatal transmission and progression to AIDS } \\
\text { were not affected by APOBEC } 3 G \text { H186R or APOBEC } 3 G \\
\text { C40693T } \\
\text { APOBEC } 3 G \text { C } 40693 \text { T was correlated with substitutions } \\
\text { in Vif motifs involved in the interaction with } \\
\text { APOBEC3G }(P=0.004)\end{array}$ & [105] \\
\hline
\end{tabular}


TABle 1: Continued.

\begin{tabular}{|c|c|c|c|}
\hline $\begin{array}{l}\text { A3 family } \\
\text { member }\end{array}$ & Series description & Main findings & Reference \\
\hline A3G & $\begin{array}{l}400 \mathrm{HIV}-1 \text {-infected individuals naive to drug therapy } \\
\text { from the Brazilian population }\end{array}$ & $\begin{array}{l}\text { Seven loci were analyzed: SNP -571 (rs5757463); -199 } \\
\text { (rs34550797); -90 (rs5750743); } 119 \text { (rs5757465); } 186 \\
\text { (rs8177832); } 197 \text { (rs3736685); } 199 \text { (rs2294367) } \\
\text { For the SNP -571, heterozygous (C/G) and } \\
\text { homozygous (G/G) individuals had lower CD4 }{ }^{+} \text {T-cell } \\
\text { counts compared to homozygous (C/C) individuals } \\
(P=0.0076)\end{array}$ & [106] \\
\hline A3G & $\begin{array}{l}93 \text { perinatally infected children with white-Hispanic } \\
\text { ethnicity, from an Argentinian pediatric cohort }\end{array}$ & $\begin{array}{l}\text { The APOBEC3G H186R and APOBEC3G C40693T } \\
\text { variants were not associated with different levels of } \\
\text { HIV-1 editing }\end{array}$ & [107] \\
\hline A3G & $\begin{array}{l}\text { 1,049 HIV-1-infected children from the Pediatric AIDS } \\
\text { Clinical Trials Group (PACTG) protocols P152 and } \\
\text { P300 ( } 60 \% \text { non-Hispanic black, } 26 \% \text { Hispanic, } 13 \% \\
\text { non-Hispanic white, and } 1 \% \text { other or unknown } \\
\text { race/ethnicity) }\end{array}$ & $\begin{array}{l}\text { APOBEC3G H186R homozygous G/G genotype was } \\
\text { associated with faster HIV-1 disease progression } \\
(P=0.01) \text { and central nervous system (CNS) } \\
\text { impairment }(P=0.02) \\
\text { APOBEC3G F119F-C allele was associated with } \\
\text { protection against disease progression and CNS } \\
\text { impairment in both additive and dominant models } \\
(P=0.002 \text { and } P=0.001 \text {, resp. }) \text { and CNS impairment } \\
(P=0.02 \text { and } P=0.007 \text {, resp. })\end{array}$ & [108] \\
\hline A3G & $\begin{array}{l}179 \mathrm{HBV} \text { chronic carriers and } 216 \text { healthy control } \\
\text { subjects from the Moroccan population }\end{array}$ & $\begin{array}{l}\text { No significant difference in the frequencies of } \\
A P O B E C 3 G \text { H186R genotype between patients with } \\
\text { chronic hepatitis B and control subjects }\end{array}$ & {$[98]$} \\
\hline $\mathrm{A} 3 \mathrm{H}$ & $\begin{array}{l}70 \text { Italian HIV-exposed seronegative individuals and } \\
\text { their HIV-1-infected sexual partners }\end{array}$ & $\begin{array}{l}\text { The } A P O B E C 3 H \text { haplotype I was found in a higher } \\
\text { frequency in the exposed seronegative compared to the } \\
\mathrm{HIV}^{+} \text {individuals }(P=0.0056) \text {, suggesting a protection } \\
\text { from sexually transmitted HIV- } 1 \text { infection }\end{array}$ & [109] \\
\hline $\mathrm{A} 3 \mathrm{H}$ & 96 recently HIV-1-infected treatment-naïve adults & $\begin{array}{l}68 \text { SNPs were analyzed } \\
\text { Homozygous carriers of an } A P O B E C 3 H \text { risk haplotype } \\
\text { (A3Hrh) had lower GA } \rightarrow \text { AA }(\mathrm{A} 3 \mathrm{~F}) \text { sequence editing } \\
\text { on proviral HIV-1 vif sequence }(P=0.01) \text { and lower } \\
\text { HIV-1 RNA levels }(P=0.015)\end{array}$ & {$[110]$} \\
\hline
\end{tabular}

8 of $A P O B E C 3 B$, which results in the complete removal of the $A P O B E C 3 B$ coding region, has been found in different human populations. Its frequency varies among ethnic groups, being more prevalent in East Asians, Amerindians, and Oceanic populations (36.9\%, 57.7\%, and $92.9 \%$, resp.) but rare among Africans and Europeans (0.9\% and 6\%, resp.) [232]. This polymorphism has been associated with increased risk for persistent HBV infection and for the development of HBV-associated hepatocellular carcinoma. Due to the $\mathrm{A} 3 \mathrm{~B}$ ability of restricting $\mathrm{HBV}$, it has been suggested that this gene deletion can result in reduced viral clearance, culminating with persistent infection [97]. In other studies, the homozygosity status for the deletion was associated with mild liver fibrosis, but not with a chronic carrier status [95], and with faster progression of liver disease [98]. Homozygous individuals for this deletion have also been reported with an increased risk for HIV acquisition, for a higher viral set point and for progression to AIDS [94], yet no effect was found on susceptibility to HIV infection and AIDS in Japanese or Indian populations [96].

Several polymorphisms in the $A P O B E C 3 G$ gene have also been described. In a study with 3,073 HIV patients from 6 different cohorts, a variant at $A P O B E C 3 G$ exon 4, H186R, was frequently found in African Americans (37\%) but rare in European American $(<3 \%)$ and in Europeans (5\%). This polymorphism was associated with $\mathrm{CD}^{+}{ }^{+} \mathrm{T}$-cell decline and with accelerated progression to AIDS-defining conditions in African Americans [99]. In another study with South African infected women, H186R was associated with higher HIV viral loads, and an extragenic mutation (rs35228531) was associated with decreased CD $4{ }^{+}$T-cell levels [104]. In a study with HIV-1-infected children from Pediatric AIDS Clinical Trials Group (PACTG) protocols P152 and P300, the H186R and F119F variants were associated with altered HIV-1-related disease progression and central nervous system impairment [108]. However, no correlation was found between H186R and disease progression in a French cohort [100]. This polymorphism has not been found in Indians [103]. Another APOBEC3G gene polymorphism, C40693T, was associated with an increased risk of HIV infection in a cohort of 122 Caucasian individuals highly exposed to HIV1 [102]. Finally, the APOBEC3G SNP-571 (rs5757463) was associated with lower $\mathrm{CD}^{+}{ }^{+} \mathrm{T}$-cell counts in homo- and heterozygosis in a group of HIV-1-infected individuals naive to drug therapy from Brazil [106].

$A P O B E C 3 H$ gene is also polymorphic, with seven haplotypes identified in human populations so far (named from I to VII). Of them, only three (II, V, and VII) seem to 
originate a stable $\mathrm{A} 3 \mathrm{H}$ protein, and have a higher anti-HIV-1 activity $[156,157,233]$. APOBEC3H haplotype II has also been reported to potently restrict HTLV-1 [189]. Some of these haplotypes have a variable frequency. Haplotype 2 is present in high frequency in African populations [233]; haplotype $\mathrm{V}$ is more frequently detected in African-Americans, Caribbeans, and Chinese, while haplotype VII was rarer and found only in European Caucasians [157].

A comprehensive list of studies that described the association of particular $A P O B E C$ gene variants with viral infections of disease outcomes can be seen in Table 1. Despite several of these so-called candidate gene analysis studies identified definite associations, particularly in the context of HIV and $\mathrm{HBV}$ infections, they were not confirmed in genome-wide association studies (GWAS). The latter studies point mainly to a significant role of human leukocyte antigen (HLA) alleles [234-239], suggesting that the impact of $A P O B E C$ variations on viral diseases is less robust and only moderate [234].

\section{Concluding Remarks}

Innate immunity mechanisms are the first line against invading viruses and are promising targets for preventing viral infections. Some infections are life-long once established, for example, by HIV and HSV-1, and therefore innate immunity is pivotal to avoiding the unfavorable consequences of infection of the host. The APOBEC family of cytidine deaminases plays an important role within innate immunity by deteriorating the genetic information of many viruses through hypermutation-dependent and -independent mechanisms. Polymorphisms in $A P O B E C$ genes that render differences in their expression and enzymatic activity also affect viral infection outcomes, and yet currently these effects appear modest and are not evidenced by GWAS. Viruses, on their hand, evolved molecular mechanisms to counteract APOBEC effects. Diminished APOBEC activity and sublethal levels of hypermutation may favor virus evolution, by generating viable variants carrying immune escape or drug resistance mutations. Conversely, the unfavorable consequences of APOBEC upregulation, particularly its recently described carcinogenic and genotoxic potential, are important caveats that will require further assessment and will pose a challenge to strategies aiming at increasing APOBEC expression to counteract viral infections. These issues will certainly warrant continuing investigation on the role and effects of cytidine deamination in infectious diseases and cancer.

\section{Acknowledgments}

V. C. Vieira is a recipient of a Ph.D. scholarship from the Brazilian Ministry of Health. This work is part of her requirements for obtaining a Ph.D. degree at the Graduate Program in Oncology of the Brazilian Cancer Institute (INCA). M. A. Soares is sponsored by grants of the Brazilian Ministry of Health, Brazilian Research Council (CNPq) and the Rio de Janeiro State Science Foundation (FAPERJ).

\section{References}

[1] A. Iwasaki, "A virological view of innate immune recognition," Annual Review of Microbiology, vol. 66, pp. 177-196, 2012.

[2] O. Takeuchi and S. Akira, "Innate immunity to virus infection," Immunological Reviews, vol. 227, no. 1, pp. 75-86, 2009.

[3] M. R. Thompson, J. J. Kaminski, E. A. Kurt-Jones, and K. A. Fitzgerald, "Pattern recognition receptors and the innate immune response to viral infection," Viruses, vol. 3, no. 6, pp. 920-940, 2011.

[4] D. B. Stetson and R. Medzhitov, "Type I interferons in host defense," Immunity, vol. 25, no. 3, pp. 373-381, 2006.

[5] S. G. Conticello, C. J. F. Thomas, S. K. Petersen-Mahrt, and M. S. Neuberger, "Evolution of the AID/APOBEC family of polynucleotide (deoxy)cytidine deaminases," Molecular Biology and Evolution, vol. 22, no. 2, pp. 367-377, 2005.

[6] T. Muto, M. Muramatsu, M. Taniwaki, K. Kinoshita, and T. Honjo, "Isolation, tissue distribution, and chromosomal localization of the human activation-induced cytidine deaminase (AID) gene," Genomics, vol. 68, no. 1, pp. 85-88, 2000.

[7] R. Espinosa III, T. Funahashi, C. Hadjiagapiou, M. M. le Beau, and N. O. Davidson, "Assignment of the gene encoding the human apolipoprotein B mRNA editing enzyme (APOBEC1) to chromosome 12p13.1," Genomics, vol. 24, no. 2, pp. 414-415, 1994.

[8] W. Liao, S. Hong, B. H. Chann, F. B. Rudolph, S. Clark, and L. Chan, "APOBEC-2, a cardiac- and skeletal musclespecific member of the cytidine deaminase supergene family," Biochemical and Biophysical Research Communications, vol. 260, pp. 398-404, 1999.

[9] A. Jarmuz, A. Chester, J. Bayliss et al., "An anthropoid-specific locus of orphan $\mathrm{C}$ to U RNA-editing enzymes on chromosome 22," Genomics, vol. 79, no. 3, pp. 285-296, 2002.

[10] I. B. Rogozin, M. K. Basu, I. K. Jordan, Y. I. Pavlov, and E. V. Koonin, "APOBEC4, a new member of the AID/APOBEC family of polynucleotide (deoxy)cytidine deaminases predicted by computational analysis," Cell Cycle, vol. 4, no. 9, pp. 12811285, 2005.

[11] J. E. Wedekind, G. S. C. Dance, M. P. Sowden, and H. C. Smith, "Messenger RNA editing in mammals: new members of the APOBEC family seeking roles in the family business," Trends in Genetics, vol. 19, no. 4, pp. 207-216, 2003.

[12] B. Teng, C. F. Burant, and N. O. Davidson, "Molecular cloning of an apolipoprotein B messenger RNA editing protein," Science, vol. 260, no. 5115, pp. 1816-1818, 1993.

[13] R. S. Harris, S. K. Petersen-Mahrt, and M. S. Neuberger, "RNA editing enzyme APOBEC1 and some of its homologs can act as DNA mutators," Molecular Cell, vol. 10, no. 5, pp. 1247-1253, 2002.

[14] Y. Yang, Y. Yang, and H. C. Smith, "Multiple protein domains determine the cell type-specific nuclear distribution of the catalytic subunit required for apolipoprotein B mRNA editing," Proceedings of the National Academy of Sciences of the United States of America, vol. 94, no. 24, pp. 13075-13080, 1997.

[15] P. P. Lau, W. Xiong, H.-J. Zhu, S.-H. Chen, and L. Chan, "Apolipoprotein B mRNA editing is an intranuclear event that occurs posttranscriptionally coincident with splicing and polyadenylation," The Journal of Biological Chemistry, vol. 266, no. 30, pp. 20550-20554, 1991.

[16] M. P. Sowden, N. Ballatori, K. L. de Mesy Jensen, L. Hamilton Reed, and H. C. Smith, "The editosome for cytidine to uridine 
mRNA editing has a native complexity of $27 \mathrm{~S}$ : identification of intracellular domains containing active and inactive editing factors," Journal of Cell Science, vol. 115, no. 5, pp. 1027-1039, 2002.

[17] S. Anant and N. O. Davidson, "Molecular mechanisms of apolipoprotein B mRNA editing," Current Opinion in Lipidology, vol. 12, no. 2, pp. 159-165, 2001.

[18] S. Anant and N. O. Davidson, "An AU-rich sequence element (UUUN[A/U]U) downstream of the edited $\mathrm{C}$ in apolipoprotein $\mathrm{B}$ mRNA is a high-affinity binding site for Apobec-1: binding of Apobec-1 to this motif in the 3' untranslated region of c-myc increases mRNA stability," Molecular and Cellular Biology, vol. 20, no. 6, pp. 1982-1992, 2000.

[19] B. R. Rosenberg, C. E. Hamilton, M. M. Mwangi, S. Dewell, and F. N. Papavasiliou, "Transcriptome-wide sequencing reveals numerous APOBEC1 mRNA-editing targets in transcript 3' UTRs," Nature Structural \& Molecular Biology, vol. 18, no. 2, pp. 230-238, 2011.

[20] S. K. Dickerson, E. Market, E. Besmer, and F. N. Papavasiliou, "AID mediates hypermutation by deaminating single stranded DNA," The Journal of Experimental Medicine, vol. 197, no. 10, pp. 1291-1296, 2003.

[21] R. Bransteitter, P. Pham, M. D. Scharfft, and M. F. Goodman, "Activation-induced cytidine deaminase deaminates deoxycytidine on single-stranded DNA but requires the action of RNase," Proceedings of the National Academy of Sciences of the United States of America, vol. 100, no. 7, pp. 4102-4107, 2003.

[22] C. Rada, J. M. Jarvis, and C. Milstein, "AID-GFP chemirec protein increases hypermutation og Ig genes with no evidence of nuclear localization," Proceedings of the National Academy of Sciences of the United States of America, vol. 99, no. 10, pp. 70037008, 2002.

[23] S. S. Brar, M. Watson, and M. Diaz, "Activation-induced cytosine deaminase (AID) is actively exported out of the nucleus but retained by the induction of DNA breaks," The Journal of Biological Chemistry, vol. 279, no. 25, pp. 26395-26401, 2004.

[24] S. Ito, H. Nagaoka, R. Shinkura et al., "Activation-induced cytidine deaminase shuttles between nucleus and cytoplasm like apolipoprotein B mRNA editing catalytic polypeptide 1," Proceedings of the National Academy of Sciences of the United States of America, vol. 101, no. 7, pp. 1975-1980, 2004.

[25] K. M. McBride, V. Barreto, A. R. Ramiro, P. Stavropoulos, and M. C. Nussenzweig, "Somatic hypermutation is limited by CRM1-dependent nuclear export of activation-induced deaminase," The Journal of Experimental Medicine, vol. 199, no. 9, pp. 1235-1244, 2004.

[26] M. Muramatsu, K. Kinoshita, S. Fagarasan, S. Yamada, Y. Shinkai, and T. Honjo, "Class switch recombination and hypermutation require activation-induced cytidine deaminase (AID), a potential RNA editing enzyme," Cell, vol. 102, no. 5, pp. 553-563, 2000.

[27] J. M. Di Noia and M. S. Neuberger, "Molecular mechanisms of antibody somatic hypermutation," Annual Review of Biochemistry, vol. 76, pp. 1-22, 2007.

[28] M. Muramatsu, V. S. Sankaranand, S. Anant et al., "Specific expression of activation-induced cytidine deaminase (AID), a novel member of the RNA-editing deaminase family in germinal center B cells," The Journal of Biological Chemistry, vol. 274, no. 26, pp. 18470-18476, 1999.

[29] C. Popp, W. Dean, S. Feng et al., "Genome-wide erasure of DNA methylation in mouse primordial germ cells is affected by AID deficiency," Nature, vol. 463, no. 7284, pp. 1101-1105, 2010.
[30] N. Bhutani, J. J. Brady, M. Damian, A. Sacco, S. Y. Corbel, and H. M. Blau, "Reprogramming towards pluripotency requires AIDdependent DNA demethylation," Nature, vol. 463, no. 7284, pp. 1042-1047, 2010.

[31] J. U. Guo, Y. Su, C. Zhong, G.-L. Ming, and H. Song, "Hydroxylation of 5-methylcytosine by TET1 promotes active DNA demethylation in the adult brain," Cell, vol. 145, no. 3, pp. 423434, 2011

[32] Y. Sato, H. C. Probst, R. Tatsumi, Y. Ikeuchi, M. S. Neuberger, and C. Rada, "Deficiency in APOBEC2 leads to a shift in muscle fiber type, diminished body mass, and myopathy," The Journal of Biological Chemistry, vol. 285, no. 10, pp. 7111-7118, 2010.

[33] J. E. Wedekind, R. Gillilan, A. Janda et al., "Nanostructures of APOBEC3G support a hierarchical assembly model of high molecular mass ribonucleoprotein particles from dimeric subunits," The Journal of Biological Chemistry, vol. 281, no. 50, pp. 38122-38126, 2006.

[34] F. Navarro, B. Bollman, H. Chen et al., "Complementary function of the two catalytic domains of APOBEC3G," Virology, vol. 333, no. 2, pp. 374-386, 2005.

[35] R. C. L. Beale, S. K. Petersen-Mahrt, I. N. Watt, R. S. Harris, C. Rada, and M. S. Neuberger, "Comparison of the differential context-dependence of DNA deamination by APOBEC enzymes: correlation with mutation spectra in vivo," Journal of Molecular Biology, vol. 337, no. 3, pp. 585-596, 2004.

[36] A. E. Armitage, A. Katzourakis, T. de Oliveira et al., "Conserved footprints of APOBEC3G on hypermutated human immunodeficiency virus type 1 and human endogenous retrovirus HERVK(HML2) sequences," Journal of Virology, vol. 82, no. 17, pp. 8743-8761, 2008.

[37] K. N. Bishop, R. K. Holmes, A. M. Sheehy, N. O. Davidson, S.J. Cho, and M. H. Malim, "Cytidine deamination of retroviral DNA by diverse APOBEC proteins," Current Biology, vol. 14, no. 15, pp. 1392-1396, 2004.

[38] R. S. Harris, K. N. Bishop, A. M. Sheehy et al., "DNA deamination mediates innate immunity to retroviral infection," Cell, vol. 113, no. 6, pp. 803-809, 2003.

[39] H. P. Bogerd, H. L. Wiegand, B. P. Doehle, K. K. Lueders, and B. R. Cullen, "APOBEC3A and APOBEC3B are potent inhibitors of LTR-retrotransposon function in human cells," Nucleic Acids Research, vol. 34, no. 1, pp. 89-95, 2006.

[40] M. Kinomoto, T. Kanno, M. Shimura et al., "All APOBEC3 family proteins differentially inhibit LINE-1 retrotransposition," Nucleic Acids Research, vol. 35, no. 9, pp. 2955-2964, 2007.

[41] F. Delebecque, R. Suspène, S. Calattini et al., "Restriction of foamy viruses by APOBEC cytidine deaminases," Journal of Virology, vol. 80, no. 2, pp. 605-614, 2006.

[42] Q. Yu, D. Chen, R. König, R. Mariani, D. Unutmaz, and N. R. Landau, "APOBEC3B and APOBEC3C are potent inhibitors of simian immunodeficiency virus replication," The Journal of Biological Chemistry, vol. 279, no. 51, pp. 53379-53386, 2004.

[43] J. L. Anderson and T. J. Hope, "APOBEC3G restricts early HIV1 replication in the cytoplasm of target cells," Virology, vol. 375, no. 1, pp. 1-12, 2008.

[44] K. N. Bishop, R. K. Holmes, and M. H. Malim, "Antiviral potency of APOBEC proteins does not correlate with cytidine deamination," Journal of Virology, vol. 80, no. 17, pp. 8450-8458, 2006.

[45] K. N. Bishop, M. Verma, E.-Y. Kim, S. M. Wolinsky, and M. H. Malim, "APOBEC3G inhibits elongation of HIV-1 reverse transcripts," PLoS Pathogens, vol. 4, no. 12, Article ID e1000231, 2008. 
[46] M. D. Stenglein, M. B. Burns, M. Li, J. Lengyel, and R. S. Harris, "APOBEC3 proteins mediate the clearance of foreign DNA from human cells," Nature Structural \& Molecular Biology, vol. 17, no. 2, pp. 222-229, 2010.

[47] R. Suspène, M.-M. Aynaud, D. Guétard et al., "Somatic hypermutation of human mitochondrial and nuclear DNA by APOBEC3 cytidine deaminases, a pathway for DNA catabolism," Proceedings of the National Academy of Sciences of the United States of America, vol. 108, no. 12, pp. 4858-4863, 2011.

[48] M. B. Burns, L. Lackey, M. A. Carpenter et al., "APOBEC3B is an enzymatic source of mutation in breast cancer," Nature, vol. 494, pp. 366-370, 2013.

[49] R. P. Bennett, V. Presnyak, J. E. Wedekind, and H. C. Smith, "Nuclear exclusion of the HIV-1 host defense factor APOBEC3G requires a novel cytoplasmic retention signal and is not dependent on RNA binding," The Journal of Biological Chemistry, vol. 283, no. 12, pp. 7320-7327, 2008.

[50] L. Lackey, Z. L. Demorest, A. M. Land, J. F. Hultquist, W. L. Brown, and R. S. Harris, "APOBEC3B and AID have similar nuclear import mechanisms," Journal of Molecular Biology, vol. 419, no. 5, pp. 301-314, 2012.

[51] M. M. H. Li and M. Emerman, "Polymorphism in human APOBEC3H affects a phenotype dominant for subcellular localization and antiviral activity," Journal of Virology, vol. 85, no. 16, pp. 8197-8207, 2011.

[52] A. M. Land, E. K. Law, M. A. Carpenter, L. Lackey, W. L. Brown, and R. S. Harris, "Endogenous APOBEC3A is cytoplasmic and non-genotoxic," The Journal of Biological Chemistry, 2013.

[53] Y.-L. Chiu, V. B. Soros, J. F. Kreisberg, K. Stopak, W. Yonemoto, and W. C. Greene, "Cellular APOBEC3G restricts HIV-1 infection in resting CD4+ T cells," Nature, vol. 435, no. 7038, pp. 108114, 2005.

[54] Y.-L. Chiu and W. C. Greene, "The APOBEC3 cytidine deaminases: an innate defensive network opposing exogenous retroviruses and endogenous retroelements," Annual Review of Immunology, vol. 26, pp. 317-353, 2008.

[55] H. C. Smith, R. P. Bennett, A. Kizilyer, W. M. McDougall, and K. M. Prohaska, "Functions and regulation of the APOBEC family of proteins," Seminars in Cell and Developmental Biology, vol. 23, no. 3, pp. 258-268, 2012.

[56] X. Wang, P. T. Dolan, Y. Dang, and Y.-H. Zheng, "Biochemical differentiation of APOBEC3F and APOBEC3G proteins associated with HIV-1 life cycle," The Journal of Biological Chemistry, vol. 282, no. 3, pp. 1585-1594, 2007.

[57] L. Tan, P. T. N. Sarkis, T. Wang, C. Tian, and X.-F. Yu, "Sole copy of Z2-type human cytidine deaminase APOBEC3H has inhibitory activity against retrotransposons and HIV-1," The FASEB Journal, vol. 23, no. 1, pp. 279-287, 2009.

[58] A. M. Niewiadomska, C. Tian, L. Tan, T. Wang, P. T. N. Sarkis, and X.-F. Yu, "Differential inhibition of long interspersed element 1 by APOBEC3 does not correlate with high-molecularmass-complex formation or P-body association," Journal of Virology, vol. 81, no. 17, pp. 9577-9583, 2007.

[59] J. F. Kreisberg, W. Yonemoto, and W. C. Greene, "Endogenous factors enhance HIV infection of tissue naive CD4 T cells by stimulating high molecular mass APOBEC3G complex formation," The Journal of Experimental Medicine, vol. 203, no. 4, pp. 865-870, 2006.

[60] K. S. Stopak, Y.-L. Chiu, J. Kropp, R. M. Grant, and W. C. Greene, "Distinct patterns of cytokine regulation of APOBEC3G expression and activity in primary lymphocytes, macrophages, and dendritic cells," The Journal of Biological Chemistry, vol. 282, no. 6, pp. 3539-3546, 2007.

[61] P. J. Ellery, E. Tippett, Y.-L. Chiu et al., "The CD16+ monocyte subset is more permissive to infection and preferentially harbors HIV-1 in vivo," Journal of Immunology, vol. 178, no. 10, pp. 6581-6589, 2007.

[62] M. Kamata, Y. Nagaoka, and I. S. Y. Chen, "Reassessing the role of APOBEC3G in human immunodeficiency virus type 1 infection of quiescent CD4+ T-cells," PLoS Pathogens, vol. 5, no. 3, Article ID e1000342, 2009.

[63] F. R. Santoni de Sio and D. Trono, "APOBEC3G-depleted resting CD4+ T cells remain refractory to HIV1 infection," PLoS ONE, vol. 4, no. 8, article e6571, 2009.

[64] V. B. Soros, W. Yonemoto, and W. C. Greene, "Newly synthesized APOBEC3G is incorporated into HIV virions, inhibited by HIV RNA, and subsequently activated by RNase H," PLoS Pathogens, vol. 3, no. 2, article e15, 2007.

[65] M. A. Khan, R. Goila-Gaur, S. Kao, E. Miyagi, R. C. Walker Jr., and K. Strebel, "Encapsidation of APOBEC3G into HIV-1 virions involves lipid raft association and does not correlate with APOBEC3G oligomerization," Retrovirology, vol. 6, article 1742, 2009.

[66] J. Ma, X. Li, J. Xu et al., “The cellular source for APOBEC3G's incorporation into HIV-1," Retrovirology, vol. 8, article 2, 2011.

[67] Y.-L. Chiu, H. E. Witkowska, S. C. Hall et al., "High-molecularmass APOBEC3G complexes restrict Alu retrotransposition," Proceedings of the National Academy of Sciences of the United States of America, vol. 103, no. 42, pp. 15588-15593, 2006.

[68] S. Gallois-Montbrun, B. Kramer, C. M. Swanson et al., "Antiviral protein $\mathrm{APOBEC} 3 \mathrm{G}$ localizes to ribonucleoprotein complexes found in P bodies and stress granules," Journal of Virology, vol. 81, no. 5, pp. 2165-2178, 2007.

[69] S. Gallois-Montbrun, R. K. Holmes, C. M. Swanson et al., "Comparison of cellular ribonucleoprotein complexes associated with the APOBEC3F and APOBEC3G antiviral proteins," Journal of Virology, vol. 82, no. 11, pp. 5636-5642, 2008.

[70] S. L. Kozak, M. Marin, K. M. Rose, C. Bystrom, and D. Kabat, "The anti-HIV-1 editing enzyme APOBEC3G binds HIV-1 RNA and messenger RNAs that shuttle between polysomes and stress granules," The Journal of Biological Chemistry, vol. 281, no. 39, pp. 29105-29119, 2006.

[71] M. J. Wichroski, G. B. Robb, and T. M. Rana, "Human retroviral host restriction factors $\mathrm{APOBEC} 3 \mathrm{G}$ and $\mathrm{APOBEC} 3 \mathrm{~F}$ localize to mRNA processing bodies," PLoS Pathogens, vol. 2, no. 5, article e41, 2006.

[72] P. K. Phalora, N. M. Sherer, S. M. Wolinsky, C. M. Swanson, and M. H. Malim, "HIV-1 replication and APOBEC3 antiviral activity are not regulated by $\mathrm{P}$ bodies," Journal of Virology, vol. 86, no. 21, pp. 11712-11724, 2012.

[73] A. G. Lada, C. Frahm Krick, S. G. Kozmin et al., "Mutator effects and mutation signatures of editing deaminases produced in bacteria and yeast," Biochemistry, vol. 76, no. 1, pp. 131-146, 2011.

[74] S. G. Conticello, "Creative deaminases, self-inflicted damage, and genome evolution," Annals of the New York Academy of Sciences, vol. 1267, pp. 79-85, 2012.

[75] C. Münk, B. E. O. Jensen, J. Zielonka, D. Häussinger, and C. Kamp, "Running loose or getting lost: how HIV-1 counters and capitalizes on APOBEC3-induced mutagenesis through its Vif protein," Viruses, vol. 4, pp. 3132-3161, 2012. 
[76] F. Severi, A. Chicca, and S. G. Conticello, "Analysis of reptilian APOBEC1 suggests that RNA Editing may not be its ancestral function," Molecular Biology and Evolution, vol. 28, no. 3, pp. 1125-1129, 2011.

[77] R. S. Harris and M. T. Liddament, "Retroviral restriction by APOBEC proteins," Nature Reviews Immunology, vol. 4, no. 11, pp. 868-877, 2004.

[78] C. Münk, A. Willemsen, and I. Bravo, "An ancient history of gene duplications, fusions and losses in the evolution of APOBEC3 mutators in mammals," BMC Evolutionary Biology, vol. 12, article 71, 2012.

[79] R. S. LaRue, S. R. Jónsson, K. A. T. Silverstein et al., "The artiodactyl APOBEC3 innate immune repertoire shows evidence for a multi-functional domain organization that existed in the ancestor of placental mammals," BMC Molecular Biology, vol. 9, no. 104, pp. 1-20, 2008.

[80] C. Münk, T. Beck, J. Zielonka et al., "Functions, structure, and read-through alternative splicing of feline APOBEC3 genes," Genome Biology, vol. 9, no. 3, article R48, 2008.

[81] G. G. Schumann, "APOBEC3 proteins: major players in intracellular defence against LINE-1-mediated retrotransposition," Biochemical Society Transactions, vol. 35, no. 3, pp. 637-642, 2007.

[82] A. Koito and T. Ikeda, "Intrinsic immunity against retrotransposons by APOBEC cytidine deaminases," Frontiers in Microbiology, vol. 4, pp. 1-9, 2013.

[83] H. P. Bogerd, H. L. Wiegand, A. E. Hulme et al., "Cellular inhibitors of long interspersed element 1 and Alu retrotransposition," Proceedings of the National Academy of Sciences of the United States of America, vol. 103, no. 23, pp. 8780-8785, 2006.

[84] A. E. Hulme, H. P. Bogerd, B. R. Cullen, and J. V. Moran, "Selective inhibition of Alu retrotransposition by APOBEC3G," Gene, vol. 390, no. 1-2, pp. 199-205, 2007.

[85] C. Esnault, O. Heidmann, F. Delebecque et al., "APOBEC3G cytidine deaminase inhibits retrotransposition of endogenous retroviruses," Nature, vol. 433, no. 7024, pp. 430-433, 2005.

[86] C. Esnault, J. Millet, O. Schwartz, and T. Heidmann, "Dual inhibitory effects of APOBEC family proteins on retrotransposition of mammalian endogenous retroviruses," Nucleic Acids Research, vol. 34, no. 5, pp. 1522-1531, 2006.

[87] A. J. Schumacher, D. V. Nissley, and R. S. Harris, "APOBEC3G hypermutates genomic DNA and inhibits Tyl retrotransposition in yeast," Proceedings of the National Academy of Sciences of the United States of America, vol. 102, no. 28, pp. 9854-9859, 2005.

[88] D. A. Macduff, Z. L. Demorest, and R. S. Harris, "AID can restrict L1 retrotransposition suggesting a dual role in innate and adaptive immunity," Nucleic Acids Research, vol. 37, no. 6, pp. 1854-1867, 2009.

[89] T. Ikeda, K. H. Abd El Galil, K. Tokunaga et al., "Intrinsic restriction activity by apolipoprotein $\mathrm{B}$ mRNA editing enzyme APOBEC1 against the mobility of autonomous retrotransposons," Nucleic Acids Research, vol. 39, no. 13, pp. 5538-5554, 2011.

[90] M. Metzner, H.-M. Jäck, and M. Wabl, "LINE-1 retroelements complexed and inhibited by activation induced cytidine deaminase," PloS One, vol. 7, no. 11, article e49358, 2012.

[91] K. N. Bishop, R. K. Holmes, A. M. Sheehy, and M. H. Malim, "APOBEC-mediated editing of viral RNA," Science, vol. 305, no. 5684, article 645, 2004.
[92] T. Ikeda, T. Ohsugi, T. Kimura et al., "The antiretroviral potency of APOBEC1 deaminase from small animal species," Nucleic Acids Research, vol. 36, no. 21, pp. 6859-6871, 2008.

[93] V. Petit, D. Guétard, M. Renard et al., "Murine APOBEC1 is a powerful mutator of retroviral and cellular RNA in vitro and in vivo," Journal of Molecular Biology, vol. 385, no. 1, pp. 65-78, 2009.

[94] P. An, R. Johnson, J. Phair et al., "APOBEC3B deletion and risk of HIV-1 acquisition," The Journal of Infectious Diseases, vol. 200, no. 7, pp. 1054-1058, 2009.

[95] H. Abe, H. Ochi, T. Maekawa et al., "Effects of structural variations of APOBEC $3 \mathrm{~A}$ and APOBEC3B genes in chronic hepatitis B virus infection," Hepatology Research, vol. 39, no. 12, pp. 1159-1168, 2009.

[96] S. Itaya, T. Nakajima, G. Kaur et al., "No evidence of an association between the APOBEC3B deletion polymorphism and susceptibility to HIV infection and AIDS in Japanese and indian populations," The Journal of Infectious Diseases, vol. 202, no. 5, pp. 815-816, 2010.

[97] T. Zhang, J. Cai, J. Chang et al., "Evidence of associations of APOBEC 3B gene deletion with susceptibility to persistent $\mathrm{HBV}$ infection and hepatocellular carcinoma," Human Molecular Genetics, vol. 22, no. 6, pp. 1262-1269, 2012.

[98] S. Ezzikouri, B. Kitab, K. Rebbani et al., "Polymorphic APOBEC3 modulates chronic hepatitis B in Moroccan population," Journal of Viral Hepatitis, pp. 1-9, 2012.

[99] P. An, G. Bleiber, P. Duggal et al., "APOBEC3G genetic variants and their influence on the progression to AIDS," Journal of Virology, vol. 78, no. 20, pp. 11070-11076, 2004.

[100] H. Do, A. Vasilescu, G. Diop et al., "Exhaustive genotyping of the CEM15 (APOBEC3G) gene and absence of association with AIDS progression in a French cohort," The Journal of Infectious Diseases, vol. 191, no. 2, pp. 159-163, 2005.

[101] C. Pace, J. Keller, D. Nolan et al., "Population level analysis of human immunodeficiency virus type 1 hypermutation and its relationship with APOBEC $3 \mathrm{G}$ and vif genetic variation," Journal of Virology, vol. 80, no. 18, pp. 9259-9269, 2006.

[102] H. S. Valcke, N. F. Bernard, J. Bruneau, M. Alary, C. M. Tsoukas, and M. Roger, "APOBEC3G genetic variants and their association with risk of HIV infection in highly exposed Caucasians," AIDS, vol. 20, no. 15, pp. 1984-1986, 2006.

[103] A. Rathore, A. Chatterjee, N. Yamamoto, and T. N. Dhole, "Absence of H186R polymorphism in exon 4 of the APOBEC3G gene among north Indian individuals," Genetic Testing, vol. 12, no. 3, pp. 453-456, 2008.

[104] K. Reddy, C. A. Winkler, L. Werner, K. Mlisana, S. S. Abdool Karim, and T. Ndung'U, "Apobec3g expression is dysregulated in primary hiv-1 infection and polymorphic variants influence cd4+ t-cell counts and plasma viral load," AIDS, vol. 24, no. 2, pp. 195-204, 2010.

[105] F. A. de Maio, C. A. Rocco, P. C. Aulicino, R. Bologna, A. Mangano, and L. Sen, "Effect of HIV-1 Vif variability on progression to pediatric AIDS and its association with APOBEC3G and CUL5 polymorphisms," Infection, Genetics and Evolution, vol. 11, no. 6, pp. 1256-1262, 2011.

[106] M. C. Bizinoto, É. Leal, R. S. Diaz, and L. M. Janini, "Loci polymorphisms of the APOBEC3G gene in HIV type 1-infected Brazilians," AIDS Research and Human Retroviruses, vol. 27, no. 2, pp. 137-141, 2011.

[107] F. A. de Maio, C. A. Rocco, P. C. Aulicino, R. Bologna, A. Mangano, and L. Sen, "APOBEC3-mediated editing in 
HIV type 1 from pediatric patients and its association with APOBEC3G/CUL5 polymorphisms and Vif variability," AIDS Research and Human Retroviruses, vol. 28, no. 6, pp. 619-627, 2012.

[108] K. K. Singh, Y. Wang, K. P. Gray et al., "Genetic variants in the host restriction factor APOBEC3G are associated with HIV-1-related disease progression and central nervous system impairment in children," Journal of Acquired Immune Deficiency Syndromes, vol. 62, no. 2, pp. 197-203, 2013.

[109] R. Cagliani, S. Riva, M. Fumagalli et al., "A positively selected APOBEC $3 \mathrm{H}$ haplotype is associated with natural resistance to HIV-1 infection," Evolution, vol. 65, no. 11, pp. 3311-3322, 2011.

[110] P. A. Gourraud, A. Karaouni, J. M. Woo et al., "APOBEC3H haplotypes and HIV-1 pro-viral vif DNA sequence diversity in early untreated human immunodeficiency virus-1 infection," Human Immunology, vol. 72, no. 3, pp. 207-212, 2011.

[111] J. A. Levy, "HIV pathogenesis: 25 years of progress and persistent challenges," AIDS, vol. 23, no. 2, pp. 147-160, 2009.

[112] S. Cen, F. Guo, M. Niu, J. Saadatmand, J. Deflassieux, and L. Kleiman, "The interaction between HIV-1 gag and APOBEC3G," The Journal of Biological Chemistry, vol. 279, no. 32, pp. 33177-33184, 2004.

[113] T. M. Alce and W. Popik, "APOBEC3G is incorporated into virus-like particles by a direct interaction with HIV-1 gag nucleocapsid protein," The Journal of Biological Chemistry, vol. 279, no. 33, pp. 34083-34086, 2004.

[114] K. Luo, B. Liu, Z. Xiao et al., "Amino-terminal region of the human immunodeficiency virus type 1 nucleocapsid is required for human APOBEC3G packaging," Journal of Virology, vol. 78, no. 21, pp. 11841-11852, 2004.

[115] V.Zennou, D. Perez-Caballero, H. Göttlinger, and P. D. Bieniasz, "APOBEC3G incorporation into human immunodeficiency virus type 1 particles," Journal of Virology, vol. 78, no. 21, pp. 12058-12061, 2004.

[116] M. Douaisi, S. Dussart, M. Courcoul, G. Bessou, R. Vigne, and E. Decroly, "HIV-1 and MLV Gag proteins are sufficient to recruit APOBEC3G into virus-like particles," Biochemical and Biophysical Research Communications, vol. 321, no. 3, pp. 566$573,2004$.

[117] A. Schäfer, H. P. Bogerd, and B. R. Cullen, "Specific packaging of APOBEC3G into HIV-1 virions is mediated by the nucleocapsid domain of the gag polyprotein precursor," Virology, vol. 328, no. 2, pp. 163-168, 2004.

[118] E. S. Svarovskaia, H. Xu, J. L. Mbisa et al., "Human apolipoprotein B mRNA-editing enzyme-catalytic polypeptide-like 3G (APOBEC3G) is incorporated into HIV-1 virions through interactions with viral and nonviral RNAs," The Journal of Biological Chemistry, vol. 279, no. 34, pp. 35822-35828, 2004.

[119] A. Burnett and P. Spearman, "APOBEC3G multimers are recruited to the plasma membrane for packaging into human immunodeficiency virus type 1 virus-like particles in an RNAdependent process requiring the NC basic linker," Journal of Virology, vol. 81, no. 10, pp. 5000-5013, 2007.

[120] T. Wang, W. Zhang, C. Tian et al., "Distinct viral determinants for the packaging of human cytidine deaminases APOBEC3G and APOBEC3C," Virology, vol. 377, no. 1, pp. 71-79, 2008.

[121] D. Lecossier, F. Bouchonnet, F. Clavel, and A. J. Hance, "Hypermutation of HIV-1 DNA in the absence of the Vif protein," Science, vol. 300, no. 5622, p. 1112, 2003.

[122] B. Schröfelbauer, Q. Yu, S. G. Zeitlin, and N. R. Landau, "Human immunodeficiency virus type $1 \mathrm{Vpr}$ induces the degradation of the UNG and SMUG Uracil-DNA glycosylases," Journal of Virology, vol. 79, no. 17, pp. 10978-10987, 2005.

[123] B. Yang, K. Chen, C. Zhang, S. Huang, and H. Zhang, "Virionassociated uracil DNA glycosylase-2 and apurinic/apyrimidinic endonuclease are involved in the degradation of APOBEC3Gedited nascent HIV-1 DNA," The Journal of Biological Chemistry, vol. 282, no. 16, pp. 11667-11675, 2007.

[124] S. M. Kaiser and M. Emerman, "Uracil DNA glycosylase is dispensable for human immunodeficiency virus type 1 replication and does not contribute to the antiviral effects of the cytidine deaminase Apobec3G," Journal of Virology, vol. 80, no. 2, pp. 875-882, 2006.

[125] M.-A. Langlois and M. S. Neuberger, "Human APOBEC3G can restrict retroviral infection in avian cells and acts independently of both UNG and SMUG1," Journal of Virology, vol. 82, no. 9, pp. 4660-4664, 2008.

[126] R. K. Holmes, F. A. Koning, K. N. Bishop, and M. H. Malim, "APOBEC3F can inhibit the accumulation of HIV-1 reverse transcription products in the absence of hypermutation: comparisons with APOBEC3G," The Journal of Biological Chemistry, vol. 282, no. 4, pp. 2587-2595, 2007.

[127] Y. Iwatani, D. S. B. Chan, F. Wang et al., "Deaminaseindependent inhibition of HIV-1 reverse transcription by APOBEC3G," Nucleic Acids Research, vol. 35, no. 21, pp. 70967108, 2007.

[128] E. N. C. Newman, R. K. Holmes, H. M. Craig et al., "Antiviral function of APOBEC3G can be dissociated from cytidine deaminase activity," Current Biology, vol. 15, no. 2, pp. 166-170, 2005.

[129] J. L. Mbisa, R. Barr, J. A. Thomas et al., "Human immunodeficiency virus type $1 \mathrm{cDNAs}$ produced in the presence of APOBEC3G exhibit defects in plus-strand DNA transfer and integration," Journal of Virology, vol. 81, no. 13, pp. 7099-7110, 2007.

[130] K. Gillick, D. Pollpeter, P. Phalora, E. Y. Kim, S. M. Wolinsky, and M. H. Malim, "Suppression of HIV-1 infection by APOBEC3 proteins in primary human CD4+ T cells is associated with inhibition of processive reverse transcription as well as excessive cytidine deamination," Journal of Virology, vol. 87, no. 3, pp. 1508-1517, 2013.

[131] F. Guo, S. Cen, M. Niu, J. Saadatmand, and L. Kleiman, "Inhibition of tRNA3Lys-primed reverse transcription by human APOBEC3G during human immunodeficiency virus type 1 replication," Journal of Virology, vol. 80, no. 23, pp. 11710-11722, 2006.

[132] X.-Y. Li, F. Guo, L. Zhang, L. Kleiman, and S. Cen, "APOBEC3G inhibits DNA strand transfer during HIV-1 reverse transcription," The Journal of Biological Chemistry, vol. 282, no. 44, pp. 32065-32074, 2007.

[133] X. Wang, Z. Ao, L. Chen, G. Kobinger, J. Peng, and X. Yao, "The cellular antiviral protein APOBEC3G interacts with HIV1 reverse transcriptase and inhibits its function during viral replication," Journal of Virology, vol. 86, no. 7, pp. 3777-3786, 2012.

[134] K. Luo, T. Wang, B. Liu et al., "Cytidine deaminases APOBEC3G and APOBEC3F interact with human immunodeficiency virus type 1 integrase and inhibit proviral DNA formation," Journal of Virology, vol. 81, no. 13, pp. 7238-7248, 2007.

[135] J. L. Mbisa, W. Bu, and V. K. Pathak, "APOBEC3F and APOBEC3G inhibit HIV-1 DNA integration by different mechanisms," Journal of Virology, vol. 84, no. 10, pp. 5250-5259, 2010. 
[136] N. Casartelli, F. Guivel-Benhassine, R. Bouziat, S. Brandler, O. Schwartz, and A. Moris, "The antiviral factor APOBEC3G improves CTL recognition of cultured HIV-infected T cells," The Journal of Experimental Medicine, vol. 207, no. 1, pp. 39-49, 2010.

[137] J. M. Norman, M. Mashiba, L. A. McNamara et al., "The antiviral factor APOBEC3G enhances the recognition of HIV-infected primary T cells by natural killer cells," Nature Immunology, vol. 12, no. 10, pp. 975-983, 2011.

[138] A. M. Sheehy, N. C. Gaddis, and M. H. Malim, "The antiretroviral enzyme APOBEC3G is degraded by the proteasome in response to HIV-1 Vif," Nature Medicine, vol. 9, no. 11, pp. 14041407, 2003.

[139] X. Yu, Y. Yu, B. Liu et al., "Induction of APOBEC3G ubiquitination and degradation by an HIV-1 Vif-Cul5-SCF complex," Science, vol. 302, no. 5647, pp. 1056-1060, 2003.

[140] S. G. Conticello, R. S. Harris, and M. S. Neuberger, "The Vif protein of HIV triggers degradation of the human antiretroviral DNA deaminase APOBEC3G," Current Biology, vol. 13, no. 22, pp. 2009-2013, 2003.

[141] K. Shirakawa, A. Takaori-Kondo, M. Kobayashi et al., "Ubiquitination of APOBEC3 proteins by the Vif-Cullin5-ElonginBElonginC complex," Virology, vol. 344, no. 2, pp. 263-266, 2006.

[142] R. Mariani, D. Chen, B. Schröfelbauer et al., "Species-specific exclusion of APOBEC3G from HIV-1 virions by Vif," Cell, vol. 114, no. 1, pp. 21-31, 2003.

[143] A. Mehle, B. Strack, P. Ancuta, C. Zhang, M. McPike, and D. Gabuzda, "Vif overcomes the innate antiviral activity of APOBEC3G by promoting its degradation in the ubiquitinproteasome pathway," The Journal of Biological Chemistry, vol. 279, no. 9, pp. 7792-7798, 2004.

[144] S. Opi, S. Kao, R. Goila-Gaur et al., "Human immunodeficiency virus type 1 Vif inhibits packaging and antiviral activity of a degradation-resistant APOBEC3G variant," Journal of Virology, vol. 81, no. 15, pp. 8236-8246, 2007.

[145] S. Kao, M. A. Khan, E. Miyagi, R. Plishka, A. Buckler-White, and K. Strebel, "The human immunodeficiency virus type 1 Vif protein reduces intracellular expression and inhibits packaging of APOBEC3G (CEM15), a cellular inhibitor of virus infectivity," Journal of Virology, vol. 77, no. 21, pp. 11398-11407, 2003.

[146] K. Stopak, C. de Noronha, W. Yonemoto, and W. C. Greene, "HIV-1 Vif blocks the antiviral activity of APOBEC3G by impairing both its translation and intracellular stability," Molecular Cell, vol. 12, no. 3, pp. 591-601, 2003.

[147] G. Mercenne, S. Bernacchi, D. Richer et al., "HIV-1 Vif binds to APOBEC3G mRNA and inhibits its translation," Nucleic Acids Research, vol. 38, no. 2, pp. 633-646, 2009.

[148] C. Chaipan, J. L. Smith, W. S. Hu, and V. K. Pathak, "APOBEC3G restricts HIV-1 to a greater extent than APOBEC3F and APOBEC3DE in human primary CD4+ T cells and macrophages," Journal of Virology, vol. 87, no. 1, pp. 444-453, 2013.

[149] L. C. F. Mulder, M. Ooms, S. Majdak et al., "Moderate influence of human APOBEC3F on HIV-1 replication in primary lymphocytes," Journal of Virology, vol. 84, no. 18, pp. 9613-9617, 2010.

[150] M. T. Liddament, W. L. Brown, A. J. Schumacher, and R. S. Harris, "APOBEC3F properties and hypermutation preferences indicate activity against HIV-1 in vivo," Current Biology, vol. 14, no. 15, pp. 1385-1391, 2004.

[151] H. L. Wiegand, B. P. Doehle, H. P. Bogerd, and B. R. Cullen, "A second human antiretroviral factor, APOBEC3F, is suppressed by the HIV-1 and HIV-2 Vif proteins," The EMBO Journal, vol. 23, no. 12, pp. 2451-2458, 2004.

[152] K. Bourara, T. J. Liegler, and R. M. Grant, "Target cell APOBEC3C can induce limited G-to-A mutation in HIV-1," PLoS Pathogens, vol. 3, no. 10, pp. 1477-1485, 2007.

[153] Y. Dang, M. S. Lai, X. Wang, Y. Han, R. Lampen, and Y.-H. Zheng, "Human cytidine deaminase APOBEC3H restricts HIV1 replication," The Journal of Biological Chemistry, vol. 283, no. 17, pp. 11606-11614, 2008.

[154] Y. Dang, X. Wang, W. J. Esselman, and Y.-H. Zheng, "Identification of APOBEC3DE as another antiretroviral factor from the human APOBEC family," Journal of Virology, vol. 80, no. 21, pp. 10522-10533, 2006.

[155] B. P. Doehle, A. Schäfer, and B. R. Cullen, "Human APOBEC3B is a potent inhibitor of HIV-1 infectivity and is resistant to HIV-1 Vif," Virology, vol. 339, no. 2, pp. 281-288, 2005.

[156] A. Harari, M. Ooms, L. C. F. Mulder, and V. Simon, "Polymorphisms and splice variants influence the antiretroviral activity of Human APOBEC3H," Journal of Virology, vol. 83, no. 1, pp. 295-303, 2009.

[157] X. Wang, A. Abudu, S. Son, Y. Dang, P. J. Venta, and Y.$\mathrm{H}$. Zheng, "Analysis of human APOBEC3H haplotypes and anti-human immunodeficiency virus type 1 activity," Journal of Virology, vol. 85, no. 7, pp. 3142-3152, 2011.

[158] J. S. Albin and R. S. Harris, "Interactions of host APOBEC3 restriction factors with HIV-1 in vivo: implications for therapeutics," Expert Reviews in Molecular Medicine, vol. 12, no. e4, pp. $1-26,2010$.

[159] J. A. Vázquez-Pérez, C. E. Ormsby, R. Hernández-Juan, K. J. Torres, and G. Reyes-Terán, "APOBEC3G mRNA expression in exposed seronegative and early stage HIV infected individuals decreases with removal of exposure and with disease progression," Retrovirology, vol. 6, article 23, 2009.

[160] A. M. Land, T. B. Ball, M. Luo et al., "Human immunodeficiency virus (HIV) type 1 proviral hypermutation correlates with CD4 count in HIV-infected women from Kenya," Journal of Virology, vol. 82, no. 16, pp. 8172-8182, 2008.

[161] Y. Kourteva, M. de Pasquale, T. Allos, C. McMunn, and R. T. D’Aquila, "APOBEC3G expression and hypermutation are inversely associated with human immunodeficiency virus type 1 (HIV-1) burden in vivo," Virology, vol. 430, pp. 1-9, 2012.

[162] N. K. Ulenga, A. D. Sarr, D. Hamel, J.-L. Sankale, S. Mboup, and P. J. Kanki, "The level of APOBEC3G (hA3G)-related Gto-A mutations does not correlate with viral load in HIV type 1-infected individuals," AIDS Research and Human Retroviruses, vol. 24, no. 10, pp. 1285-1290, 2008.

[163] A. Piantadosi, D. Humes, B. Chohan, R. S. McClelland, and J. Overbaugh, "Analysis of the percentage of human immunodeficiency virus type 1 sequences that are hypermutated and markers of disease progression in a longitudinal cohort, including one individual with a partially defective vif," Journal of Virology, vol. 83, no. 16, pp. 7805-7814, 2009.

[164] N. D. Amoêdo, A. O. Afonso, S. M. Cunha, R. H. Oliveira, E. S. Machado, and M. A. Soares, "Expression of APOBEC3G/3F and G-to-A hypermutation levels in HIV-1-infected children with different profiles of disease progression," PloS One, vol. 6, no. 8, article e24118, 2011.

[165] X. Jin, A. Brooks, H. Chen, R. Bennett, R. Reichman, and H. Smith, "APOBEC3G/CEM15 (hA3G) mRNA levels associate inversely with human immunodeficiency virus viremia," Journal of Virology, vol. 79, no. 17, pp. 11513-11516, 2005. 
[166] M. Zhao, W. Geng, Y. Jiang et al., "The associations of hA3G and hA3B mRNA levels with HIV disease progression among HIV-infected individuals of China," Journal of Acquired Immune Deficiency Syndromes, vol. 53, supplement 1, pp. S4-S9, 2010.

[167] N. K. Ulenga, A. D. Sarr, S. Thakore-Meloni, J.-L. Sankalé, G. Eisen, and P. J. Kanki, "Relationship between human immunodeficiency type 1 infection and expression of human APOBEC3G and APOBEC3F," The Journal of Infectious Diseases, vol. 198, no. 4, pp. 486-492, 2008.

[168] S.-J. Cho, H. Drechsler, R. C. Burke, M. Q. Arens, W. Powderly, and N. O. Davidson, "APOBEC3F and APOBEC3G mRNA levels do not correlate with human immunodeficiency virus type 1 plasma viremia or CD4+ T-cell count," Journal of Virology, vol. 80, no. 4, pp. 2069-2072, 2006.

[169] M. Biasin, L. Piacentini, S. Lo Caputo et al., "Apolipoprotein B mRNA-editing enzyme, catalytic polypeptide-like 3G: a possible role in the resistance to HIV of HIV-exposed seronegative individuals," The Journal of Infectious Diseases, vol. 195, no. 7, pp. 960-964, 2007.

[170] T. Ejima, M. Hirota, T. Mizukami, M. Otsuka, and M. Fujita, "An anti-HIV-1 compound that increases steadystate expression of apoplipoprotein B mRNA-editing enzymecatalytic polypeptide-like 3G," International Journal of Molecular Medicine, vol. 28, no. 4, pp. 613-616, 2011.

[171] S. Cen, Z.-G. Peng, X.-Y. Li et al., "Small molecular compounds inhibit HIV-1 replication through specifically stabilizing APOBEC3G," The Journal of Biological Chemistry, vol. 285, no. 22, pp. 16546-16552, 2010.

[172] R. Nathans, H. Cao, N. Sharova et al., "Small-molecule inhibition of HIV-1 Vif," Nature Biotechnology, vol. 26, no. 10, pp. 11871192, 2008.

[173] Z. Xiao, E. Ehrlich, K. Luo, Y. Xiong, and X.-F. Yu, "Zinc chelation inhibits HIV Vif activity and liberates antiviral function of the cytidine deaminase APOBEC3G," The FASEB Journal, vol. 21, no. 1, pp. 217-222, 2007.

[174] J. F. Hultquist and R. S. Harris, "Leveraging APOBEC3 proteins to alter the HIV mutation rate and combat AIDS," Future Virology, vol. 4, no. 6, pp. 605-619, 2009.

[175] L. C. F. Mulder, A. Harari, and V. Simon, "Cytidine deamination induced HIV-1 drug resistance," Proceedings of the National Academy of Sciences of the United States of America, vol. 105, no. 14, pp. 5501-5506, 2008.

[176] P. Jern, R. A. Russell, V. K. Pathak, and J. M. Coffin, "Likely role of APOBEC3G-mediated G-to-A mutations in HIV-1 evolution and drug resistance," PLoS Pathogens, vol. 5, no. 4, Article ID e1000367, 2009.

[177] N. Wood, T. Bhattacharya, B. F. Keele et al., "HIV evolution in early infection: selection pressures, patterns of insertion and deletion, and the impact of APOBEC," PLoS Pathogens, vol. 5, no. 5, Article ID e1000414, 2009.

[178] G. Haché, K. Shindo, J. S. Albin, and R. S. Harris, "Evolution of HIV-1 isolates that use a novel Vif-independent mechanism to resist restriction by human APOBEC3G," Current Biology, vol. 18, no. 11, pp. 819-824, 2008.

[179] S. K. Pillai, J. K. Wong, and J. D. Barbour, "Turning up the volume on mutational pressure: is more of a good thing always better? (A case study of HIV-1 Vif and APOBEC3)," Retrovirology, vol. 5, article 26, 2008.

[180] E.-Y. Kim, T. Bhattacharya, K. Kunstman et al., "Human APOBEC3G-mediated editing can promote HIV-1 sequence diversification and accelerate adaptation to selective pressure," Journal of Virology, vol. 84, no. 19, pp. 10402-10405, 2010.
[181] H. A. Sadler, M. D. Stenglein, R. S. Harris, and L. M. Mansky, "APOBEC3G contributes to HIV-1 variation through sublethal mutagenesis," Journal of Virology, vol. 84, no. 14, pp. 7396-7404, 2010.

[182] S. Fourati, I. Malet, S. Lambert et al., "E138K and M184I mutations in HIV-1 reverse transcriptase coemerge as a result of APOBEC3 editing in the absence of drug exposure," AIDS, vol. 26, no. 13, pp. 1619-1624, 2012.

[183] M. E. Olson, M. Li, R. S. Harris, and D. A. Harki, "Smallmolecule APOBEC3G DNA cytosine deaminase inhibitors based on a 4-amino-1, 2, 4-triazole-3-thiol scaffold," ChemMedChem, vol. 8, pp. 112-117, 2013.

[184] M. Li, S. M. D. Shandilya, M. A. Carpenter et al., "First-in-class small molecule inhibitors of the single-strand DNA cytosine deaminase APOBEC3G," ACS Chemical Biology, vol. 7, no. 3, pp. 506-517, 2012.

[185] M. Matsuoka and K.-T. Jeang, "Human T-cell leukaemia virus type 1 (HTLV-1) infectivity and cellular transformation," Nature Reviews Cancer, vol. 7, no. 4, pp. 270-280, 2007.

[186] P. Kannian and P. L. Green, "Human T lymphotropic virus type 1 (HTLV-1): molecular biology and oncogenesis," Viruses, vol. 2, no. 9, pp. 2037-2077, 2010.

[187] J. H. Richardson, A. J. Edwards, J. K. Cruickshank, P. Rudge, and A. G. Dalgleish, "In vivo cellular tropism of human T-cell leukemia virus type 1," Journal of Virology, vol. 64, no. 11, pp. 5682-5687, 1990.

[188] E. W. Refsland, M. D. Stenglein, K. Shindo, J. S. Albin, W. L. Brown, and R. S. Harris, "Quantitative profiling of the full APOBEC3 mRNA repertoire in lymphocytes and tissues: implications for HIV-1 restriction," Nucleic Acids Research, vol. 38, no. 13, pp. 4274-4284, 2010.

[189] M. Ooms, A. Krikoni, A. K. Kress, V. Simon, and C. Münk, "APOBEC3A, APOBEC3B, and APOBEC3H haplotype 2 restrict human T-lymphotropic virus type 1," Journal of Virology, vol. 86, no. 11, pp. 6097-6108, 2012.

[190] J.-P. Vartanian, U. Plikat, M. Henry et al., "HIV genetic variation is directed and restricted by DNA precursor availability," Journal of Molecular Biology, vol. 270, no. 2, pp. 139-151, 1997.

[191] J. Fan, M. Guangyong, K. Nosaka et al., "APOBEC3G generates nonsense mutations in human T-cell leukemia virus type 1 proviral genomes in vivo," Journal of Virology, vol. 84, no. 14, pp. 7278-7287, 2010.

[192] R. Mahieux, R. Suspène, F. Delebecque et al., "Extensive editing of a small fraction of human T-cell leukemia virus type 1 genomes by four APOBEC3 cytidine deaminases," Journal of General Virology, vol. 86, no. 9, pp. 2489-2494, 2005.

[193] A. Sasada, A. Takaori-Kondo, K. Shirakawa et al., "APOBEC3G targets human T-cell leukemia virus type 1," Retrovirology, vol. 2, pp. 1-10, 2005.

[194] E. Wattel, J.-P. Vartanian, C. Pannetier, and S. Wain-Hobson, "Clonal expansion of human T-cell leukemia virus type Iinfected cells in asymptomatic and symptomatic carriers without malignancy," Journal of Virology, vol. 69, no. 5, pp. 28632868, 1995.

[195] M. Cavrois, S. Wain-Hobson, A. Gessain, Y. Plumelle, and E. Wattel, "Adult T-cell leukemia/lymphoma on a background of clonally expanding human T-cell leukemia virus type-1-positive cells," Blood, vol. 88, no. 12, pp. 4646-4650, 1996.

[196] M. Cavrois, I. Leclercq, O. Gout, A. Gessain, S. Wain-Hobson, and E. Wattel, "Persistent oligoclonal expansion of human T-cell leukemia virus type 1-infected circulating cells in patients with 
Tropical spastic paraparesis/HTLV-1 associated myelopathy," Oncogene, vol. 17, no. 1, pp. 77-82, 1998.

[197] D. Derse, S. A. Hill, G. Princler, P. Lloyd, and G. Heidecker, "Resistance of human $\mathrm{T}$ cell leukemia virus type 1 to APOBEC3G restriction is mediated by elements in nucleocapsid," Proceedings of the National Academy of Sciences of the United States of America, vol. 104, no. 8, pp. 2915-2920, 2007.

[198] J.-H. Kao and D.-S. Chen, "Global control of hepatitis B virus infection," Lancet Infectious Diseases, vol. 2, no. 7, pp. 395-403, 2002.

[199] WHO, "HBV Fact Sheet no. 204," http://www.who.int/mediacentre/factsheets/fs204/en/.

[200] M. C. Gonzalez, R. Suspène, M. Henry, D. Guétard, S. WainHobson, and J.-P. Vartanian, "Human APOBEC1 cytidine deaminase edits HBV DNA," Retrovirology, vol. 6, article 96, 2009.

[201] C. Rösler, J. Köck, M. Kann et al., "APOBEC-mediated interference with hepadnavirus production," Hepatology, vol. 42, no. 2, pp. 301-309, 2005.

[202] R. Suspène, D. Guétard, M. Henry, P. Sommer, S. Wain-Hobson, and J.-P. Vartanian, "Extensive editing of both hepatitis B virus DNA strands by APOBEC3 cytidine deaminases in vitro and in vivo," Proceedings of the National Academy of Sciences of the United States of America, vol. 102, no. 23, pp. 8321-8326, 2005.

[203] T. F. Baumert, C. Rösler, M. H. Malim, and F. von Weizsäcker, "Hepatitis B virus DNA is subject to extensive editing by the human deaminase AP0BEC3C," Hepatology, vol. 46, no. 3, pp. 682-689, 2007.

[204] J. Köck and H. E. Blum, "Hypermutation of hepatitis B virus genomes by APOBEC3G, APOBEC3C and APOBEC3H," Journal of General Virology, vol. 89, no. 5, pp. 1184-1191, 2008.

[205] M. Henry, D. Guétard, R. Suspène, C. Rusniok, S. WainHobson, and J.-P. Vartanian, "Genetic editing of HBV DNA by monodomain human APOBEC3 cytidine deaminases and the recombinant nature of APOBEC3G," PLoS ONE, vol. 4, no. 1, article e4277, 2009.

[206] J.-P. Vartanian, M. Henry, A. Marchio et al., "Massive APOBEC3 editing of hepatitis B viral DNA in cirrhosis," PLoS Pathogens, vol. 6, no. 5, Article ID e1000928, 2010.

[207] P. Turelli, B. Mangeat, S. Jost, S. Vianin, and D. Trono, "Inhibition of Hepatitis B virus replication by APOBEC3G," Science, vol. 303, no. 5665, article 1829, 2004.

[208] D. H. Nguyen, S. Gummuluru, and J. Hu, "Deaminationindependent inhibition of hepatitis B virus reverse transcription by APOBEC3G," Journal of Virology, vol. 81, no. 9, pp. 44654472, 2007.

[209] W. Zhang, X. Zhang, C. Tian et al., "Cytidine deaminase APOBEC3B interacts with heterogeneous nuclear ribonucleoprotein $\mathrm{K}$ and suppresses hepatitis B virus expression," Cellular Microbiology, vol. 10, no. 1, pp. 112-121, 2008.

[210] M. Bonvin, F. Achermann, I. Greeve et al., "Interferon-inducible expression of APOBEC3 editing enzymes in human hepatocytes and inhibition of hepatitis B virus replication," Hepatology, vol. 43, no. 6, pp. 1364-1374, 2006.

[211] Y. Tanaka, H. Marusawa, H. Seno et al., "Anti-viral protein APOBEC3G is induced by interferon- $\alpha$ stimulation in human hepatocytes," Biochemical and Biophysical Research Communications, vol. 341, no. 2, pp. 314-319, 2006.

[212] C. Noguchi, N. Hiraga, N. Mori et al., "Dual effect of APOBEC3G on Hepatitis B virus," Journal of General Virology, vol. 88, no. 2, pp. 432-440, 2007.
[213] S. Günther, G. Sommer, U. Plikat et al., "Naturally occurring hepatitis B virus genomes bearing the hallmarks of retroviral $\mathrm{G} \rightarrow$ A hypermutation," Virology, vol. 235, no. 1, pp. 104-108, 1997.

[214] S. Margeridon-Thermet, N. S. Shulman, A. Ahmed et al., "Ultra-deep pyrosequencing of hepatitis b virus quasispecies from nucleoside and nucleotide reverse-transcriptase inhibitor (NRTI)-treated patients and NRTI-naive patients," The Journal of Infectious Diseases, vol. 199, no. 9, pp. 1275-1285, 2009.

[215] S. Proto, J. A. Taylor, S. Chokshi, N. Navaratnam, and N. V. Naoumov, "APOBEC and iNOS are not the main intracellular effectors of IFN- $\gamma$-mediated inactivation of Hepatitis B virus replication," Antiviral Research, vol. 78, no. 3, pp. 260-267, 2008.

[216] S. Jost, P. Turelli, B. Mangeat, U. Protzer, and D. Trono, "Induction of antiviral cytidine deaminases does not explain the inhibition of hepatitis B virus replication by interferons," Journal of Virology, vol. 81, no. 19, pp. 10588-10596, 2007.

[217] R. Xu, X. Zhang, W. Zhang, Y. Fang, S. Zheng, and X.-F. Yu, "Association of human APOBEC3 cytidine deaminases with the generation of hepatitis virus $\mathrm{B} \mathrm{x}$ antigen mutants and hepatocellular carcinoma," Hepatology, vol. 46, no. 6, pp. 18101820, 2007.

[218] D. Moradpour, F. Penin, and C. M. Rice, "Replication of hepatitis C virus," Nature Reviews Microbiology, vol. 5, no. 6, pp. 453-463, 2007.

[219] M. Levrero, "Viral hepatitis and liver cancer: the case of hepatitis C," Oncogene, vol. 25, no. 27, pp. 3834-3847, 2006.

[220] Z.-G. Peng, Z.-Y. Zhao, Y.-P. Li et al., "Host apolipoprotein b messenger RNA-editing enzyme catalytic polypeptide-like 3G is an innate defensive factor and drug target against hepatitis $\mathrm{C}$ virus," Hepatology, vol. 53, no. 4, pp. 1080-1089, 2011.

[221] Y. Komohara, H. Yano, S. Shichijo, K. Shimotohno, K. Itoh, and A. Yamada, "High expression of APOBEC3G in patients infected with hepatitis C virus," Journal of Molecular Histology, vol. 37, no. 8-9, pp. 327-332, 2006.

[222] M. Á. Jiménez-Sousa, R. Almansa, C. de la Fuente et al., "Gene expression profiling in the first twelve weeks of treatment in chronic hepatitis C patients," Enfermedades Infecciosas $y$ Microbiologia Clinica, vol. 29, no. 8, pp. 573-580, 2011.

[223] S. K. Pillai, M. Abdel-Mohsen, J. Guatelli et al., "Role of retroviral restriction factors in the interferon- $\alpha$-mediated suppression of HIV-1 in vivo," Proceedings of the National Academy of Sciences of the United States of America, vol. 109, no. 8, pp. 30353040, 2012.

[224] N. Muñoz, X. Castellsagué, A. B. de González, and L. Gissmann, "HPV in the etiology of human cancer," Vaccine, vol. 24, supplement 3, pp. S3/1-S3/10, 2006.

[225] J.-P. Vartanian, D. Guétard, M. Henry, and S. Wain-Hobson, "Evidence for editing of human papillomavirus DNA by APOBEC3 in benign and precancerous lesions," Science, vol. 320, no. 5873, pp. 230-233, 2008.

[226] R. Suspène, M.-M. Aynaud, S. Koch et al., "Genetic editing of herpes simplex virus 1 and epstein-barr herpesvirus genomes by Human APOBEC3 cytidine deaminases in culture and in vivo," Journal of Virology, vol. 85, no. 15, pp. 7594-7602, 2011.

[227] P. Gee, Y. Ando, H. Kitayama et al., "APOBEC1-mediated editing and attenuation of herpes simplex virus 1 DNA indicate that neurons have an antiviral role during herpes simplex encephalitis," Journal of Virology, vol. 85, no. 19, pp. 9726-9736, 2011. 
[228] R. J. Whitley, D. W. Kimberlin, and B. Roizman, "Herpes simplex viruses," Clinical Infectious Diseases, vol. 26, no. 3, pp. 541-555, 1998.

[229] R. J. Whitley and B. Roizman, "Herpes simplex virus infections," The Lancet, vol. 357, no. 9267, pp. 1513-1518, 2001.

[230] C. Chisholm and L. Lopez, "Cutaneous infections caused by herpesviridae: a review," Archives of Pathology and Laboratory Medicine, vol. 135, no. 10, pp. 1357-1362, 2011.

[231] N. Mendoza, M. Diamantis, A. Arora et al., "Mucocutaneous manifestations of Epstein-Barr virus infection," American Journal of Clinical Dermatology, vol. 9, no. 5, pp. 295-305, 2008.

[232] J. M. Kidd, T. L. Newman, E. Tuzun, R. Kaul, and E. E. Eichler, "Population stratification of a common APOBEC gene deletion polymorphism," PLoS Genetics, vol. 3, no. 4, article e63, 2007.

[233] M. OhAinle, J. A. Kerns, M. M. H. Li, H. S. Malik, and M. Emerman, "Antiretroelement activity of APOBEC3H was lost twice in recent human evolution," Cell Host \& Microbe, vol. 4, no. 3, pp. 249-259, 2008.

[234] P. An and C. A. Winkler, "Host genes associated with HIV/AIDS: advances in gene discovery," Trends in Genetics, vol. 26, no. 3, pp. 119-131, 2010.

[235] J. R. Lingappa, S. Petrovski, E. Kahle et al., "Genomewide association study for determinants of HIV-1 acquisition and viral set point in HIV-1 serodiscordant couples with quantified virus exposure," PLoS ONE, vol. 6, no. 12, article e28632, 2011.

[236] D. van Manen, A. B. van Wout, and H. Schuitemaker, "Genomewide association studies on HIV susceptibility, pathogenesis and pharmacogenomics," Retrovirology, vol. 9, no. 70, pp. 1-8, 2012.

[237] Y. Kamatani, S. Wattanapokayakit, H. Ochi et al., "A genomewide association study identifies variants in the HLA-DP locus associated with chronic hepatitis B in Asians," Nature Genetics, vol. 41, no. 5, pp. 591-595, 2009.

[238] H. Zhang, Y. Zhai, Z. Hu et al., "Genome-wide association study identifies 1 p36.22 as a new susceptibility locus for hepatocellular carcinoma in chronic hepatitis B virus carriers," Nature Genetics, vol. 42, no. 9, pp. 755-758, 2010.

[239] S. Li, J. Qian, Y. Yang et al., "GWAS identifies novel susceptibility loci on 6p21. 32 and 21q21. 3 for hepatocellular carcinoma in chronic hepatitis B virus carriers," PLoS Genetics, vol. 8, no. 7, pp. 1-8, 2012. 

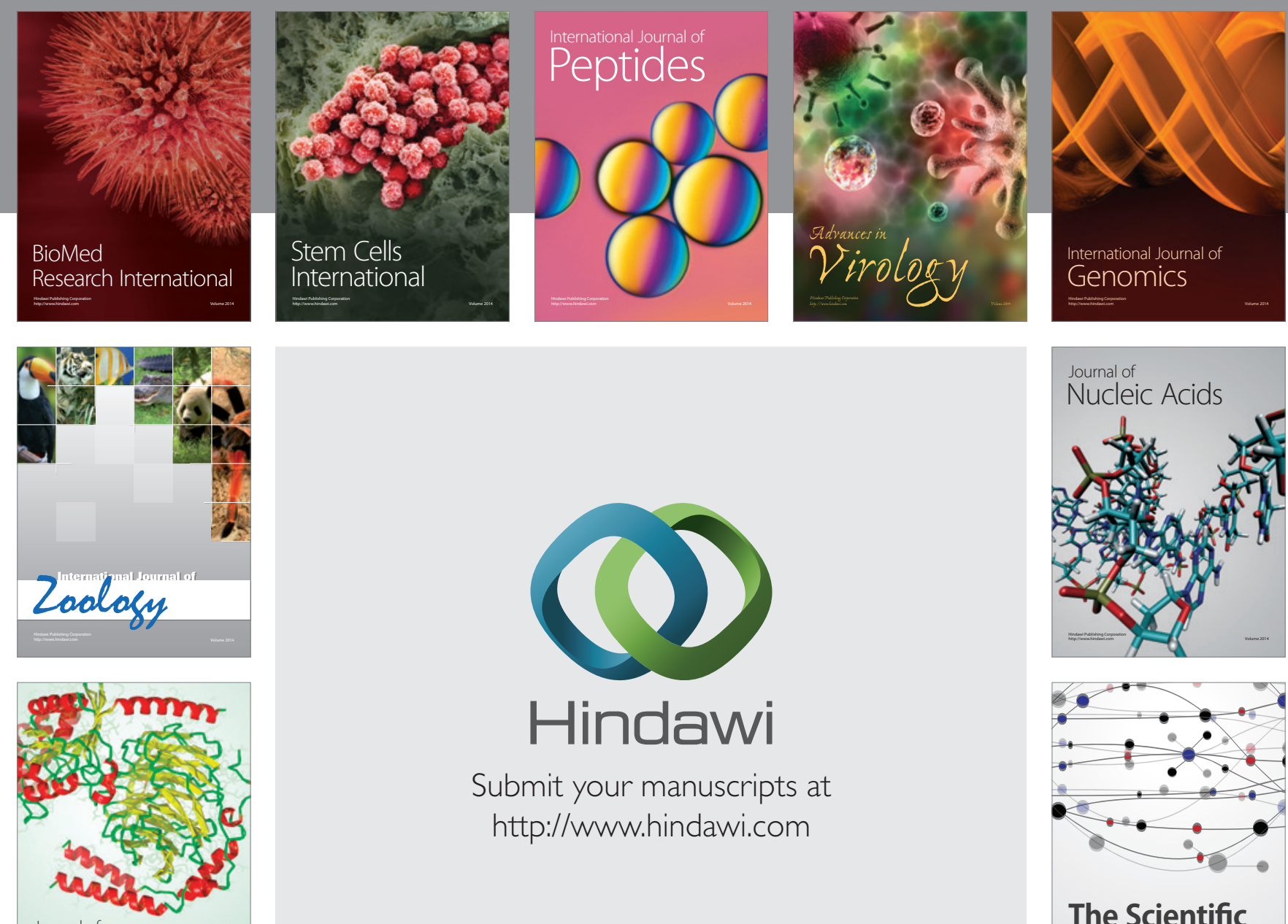

Submit your manuscripts at

http://www.hindawi.com

Journal of
Signal Transduction
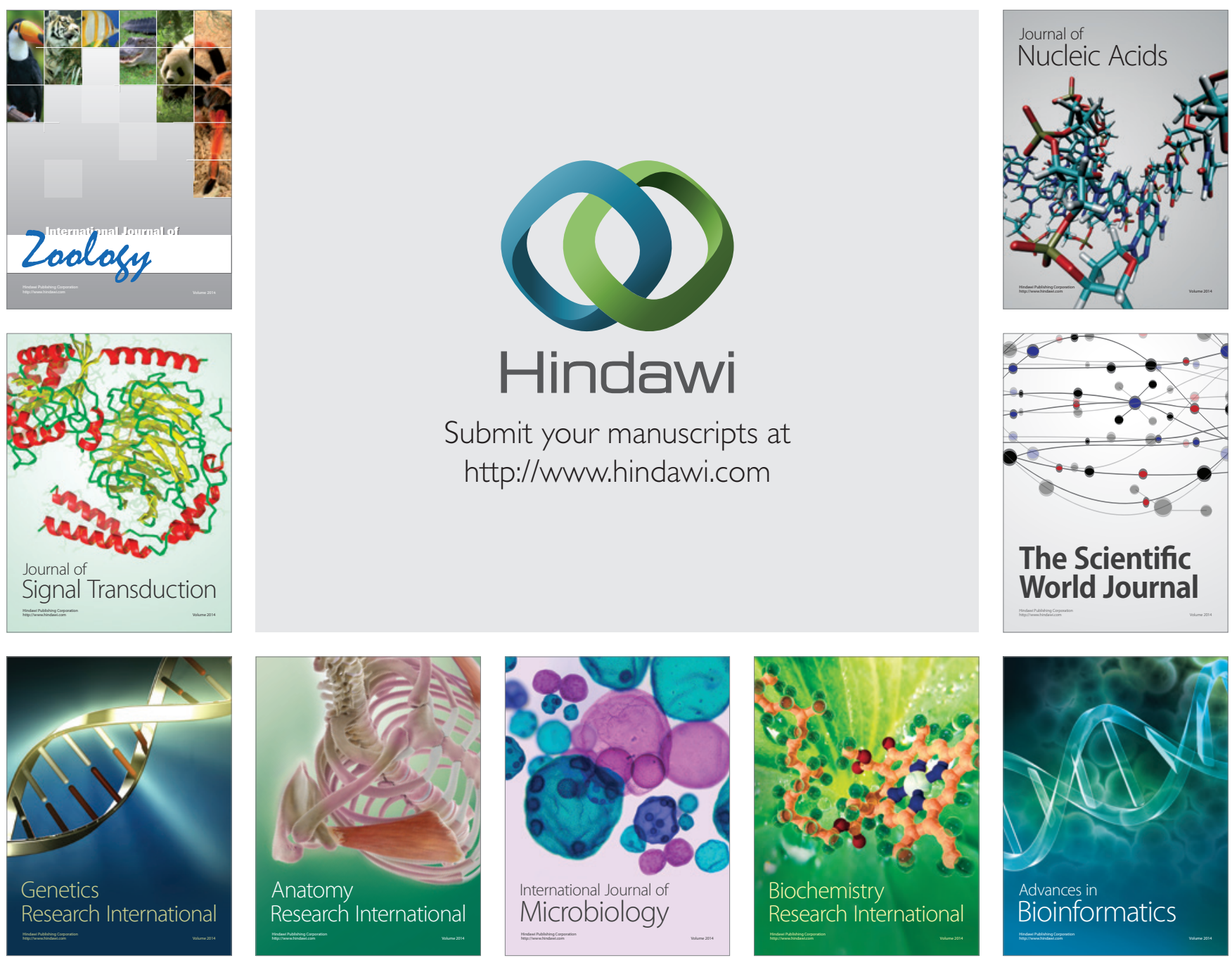

The Scientific World Journal
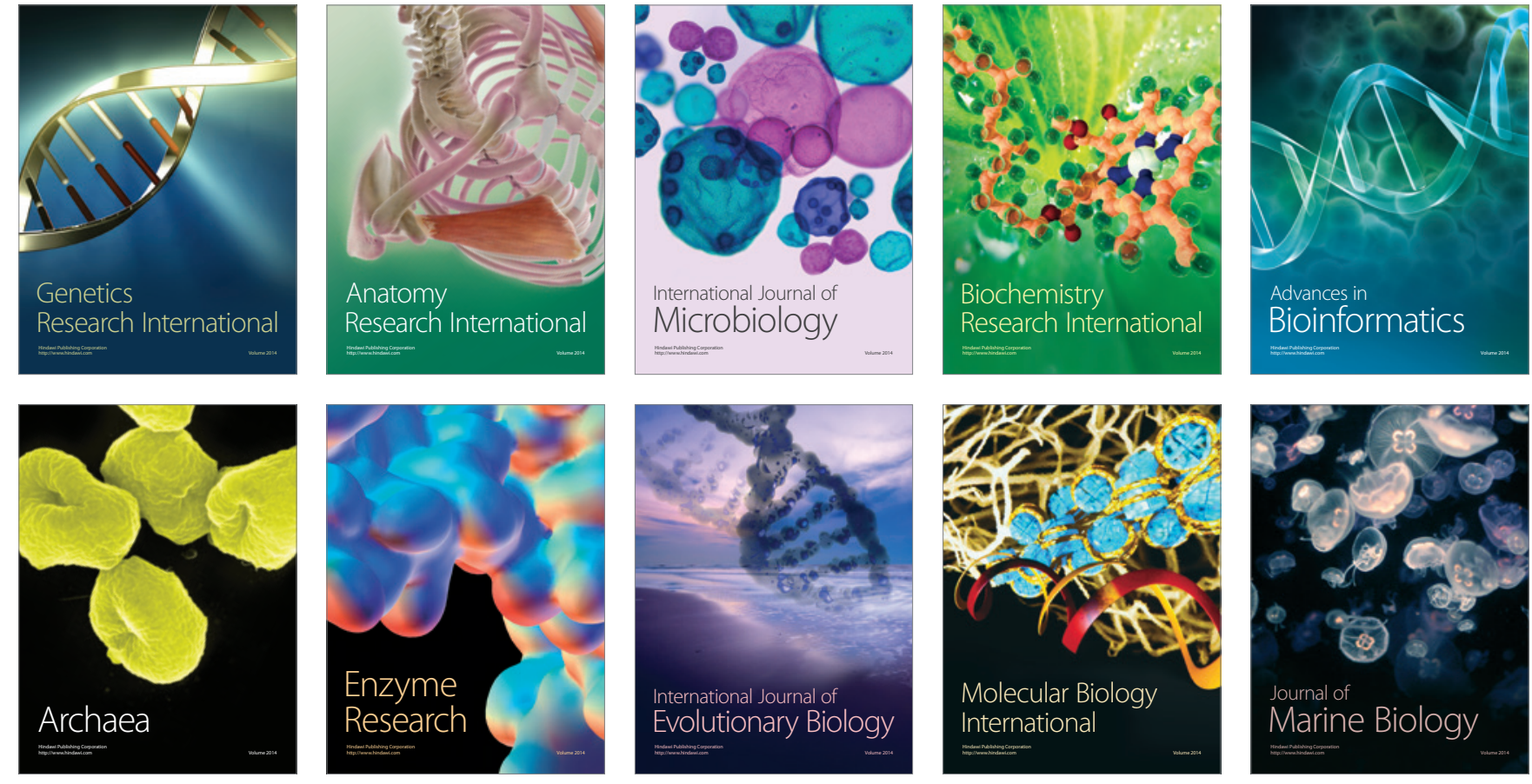